\title{
María Coleta y el Fraile Capuchino: Esclavitud, Salvación y Adjudicación de Estatus
}

\section{Rebecca J. Scott y Carlos Venegas Fornias}

Traductor. Esther Pérez y Pérez y Ana María Silva Campo

\section{(2) OpenEdition \\ Journals}

\author{
Edición electrónica \\ URL: https://journals.openedition.org/rhj/8474 \\ DOI: $10.4000 /$ rhj.8474 \\ ISSN: 0719-4153 \\ Editor \\ ACTO Editores Ltda \\ Referencia electrónica \\ Rebecca J. Scott / Carlos Venegas Fornias, «María Coleta y el Fraile Capuchino: Esclavitud, Salvación \\ y Adjudicación de Estatus», Revista Historia y Justicia [En línea], 17 | 2021, Publicado el 11 enero 2022, \\ consultado el 15 mayo 2022. URL: http://journals.openedition.org/rhj/8474 ; DOI: https://doi.org/ \\ $10.4000 /$ rhj. 8474
}

Este documento fue generado automáticamente el 15 mayo 2022.

Revista Historia y Justicia 


\title{
María Coleta y el Fraile Capuchino: Esclavitud, Salvación y Adjudicación de Estatus
}

\author{
Rebecca J. Scott y Carlos Venegas Fornias \\ Tradución : Esther Pérez y Pérez y Ana María Silva Campo
}

\section{NOTA DEL EDITOR}

NdlR: Este texto fue publicado originalmente como "María Coleta and the Capuchin Friar: Slavery, Salvation, and the Adjudication of Status", William and Mary Quarterly, 3a série, 76 (Octubre 2019): 727-762, @ Omohundro Institute of Early American History and Culture, https://doi.org/10.5309/willmaryquar.76.4.0727. Revista Historia y Justicia agradece a les autores de este texto, Rebecca J. Scott y Carlos Venegas Fornia, y a su traductores, Esther Pérez y Pérez y Ana María Silva Campo, el generoso esfuerzo para ponerlo a disposición de nuestros/as lectores/as. La revisión del texto traducido fue realizada por la Dra. Carolina González Undurraga. Respetando los usos del artículo, se mantiene aquí (a) la ortografía de todos los registros originales citados y (b) las formas de citación de los registros de archivo y bibliográficos del artículo original.

\section{NOTA DEL AUTOR}

NdA : Queremos expresar nuestro agradecimiento a Ana María Silva Campo, Daniel Varela Corredor y Andrew Walker por su excelente trabajo como asistentes de investigación. También tuvimos la suerte de contar con los consejos y las sugerencias de Arturo Abigantús, Paulina Alberto, José Luis Belmonte, Sueann Caulfield, Adriana Chira, Emily Clark, Emiliano Corral, Manuel Covo, Alejandro de la Fuente, Laurent Dubois, Anne Eller, John H. Elliott, Ada Ferrer, Pierre Force, Guadalupe García, John Garrigus, David Geggus, Malick Ghachem, Olivier Gliech, Thavolia Glymph, Thomas A. 
Green, Jean Hébrard, Marial Iglesias Utset, Jane Landers, Jean-Pierre Le Glaunec, Aims McGuinness, Dalia Muller, Francisco Ortega, Jennifer Palmer, Edgardo Pérez- Morales, Eduardo Posada Carbó, Ellen Poteet, Peter Railton, Richard Reinhardt, Terry Rey, Julia Rudolph, Romy Sánchez, the late Stanley J. Stein, Cecilia Tarruell, Richard Turits, María Cecilia Ulrickson, Joseph Vining, John Wertheimer, Oscar Zanetti, Michael Zeuske, y los lectores anónimos para la revista William and Mary Quarterly. Los participantes en el Triangle Legal History Seminar; en la Wilson Lecture de 2017 de la Escuela de Derecho de Duke; en la conferencia "Paper Technologies" de las Universidades Wesleyan y Yale; en la conferencia "Urban Slavery in the Age of Abolition" de la Universidad de Leiden; en el American Studies Program de Princeton University; en el seminario latinoamericano de Oxford; en el Cycle de Conférences Caraïbes del EHESS de París; en el Instituto Juan Marinello de la Habana; en el Legal History Colloquium de New York University; y en el Seminario de Historia Cultural de la Universidad Autónoma de Madrid, nos aportaron importantes sugerencias. Damos un agradecimiento especial al padre Dennis Dillon de la parroquia estudiantil de St. Mary, en Ann Arbor, Michigan, por darnos información sobre la administración de los últimos ritos (extremaunción). También queremos expresarle nuestro agradecimiento a Aisnara Perera Díaz, María de los Ángeles Meriño y Adriana Chira, cuyas notas al pie nos llevaron al expediente del caso de las hijas de Coleta y Andrea.

Dedicamos este ensayo a la memoria de Fernando Martínez Heredia (1939-2017), querido amigo y colega.

\section{Texto del artículo}

1 En medio de la revolución haitiana, una joven llamada Marie Louise dejó atrás las ruinas de la plantación en la que había sido esclavizada, cerca de Cap Françaisi. Como ya no era reclamada como propiedad en una colonia donde la esclavitud estaba siendo abolida, viajó hacia el este, atravesando la desolación y la guerra de la Plaine du Nord. Finalmente llegó al pueblo de Fort-Dauphin, cercano a la frontera entre SaintDomingue y Santo Domingo. Allí encontró refugio con una mujer a quien se refirió como su madrina y comenzó a trabajar a cambio de un salario ${ }^{1}$.

2 Durante los primeros meses de 1794 fuerzas militares españolas tomaron el control de Fort-Dauphin, llamándola Bayajá, pero a finales del año siguiente, el Tratado de Basilea exigió que España renunciara a su soberanía sobre Santo Domingo a favor de la República Francesa.

3 Parte de los campos circundantes estaba bajo el control de insurgentes negros de SaintDomingue que habían servido como fuerzas "auxiliares" bajo la bandera española contra los franceses. Por la zona deambulaban espías al servicio de los británicos que ansiaban controlar la amplia bahía del pueblo. Con alrededor de catorce años, Marie Louise se encontraba en un vórtice de imperios, un lugar con jurisdicciones cambiantes donde varias soberanías se traslapaban².

4 El futuro era totalmente incierto. Los soldados españoles, muchos de ellos provenientes de Cuba, se preparaban para evacuar hacia La Habana en varios navíos que esperaban anclados en el puerto. Transcurridas algunas semanas el gobernador español se mantenía en su cargo, pero el traspaso del poder a las tropas francesas 
parecía inminente. Mientras tanto, el general Gordon Forbes, comandante de las fuerzas británicas acampadas al oeste, en Môle Saint Nicholas, trataba de reclutar al resto de las tropas de "auxiliares" negros previamente comandadas por Jean-François y Georges Biassou, para que combatieran a los franceses a las órdenes británicas. Forbes también emitió una proclama dirigida a los residentes españoles de la colonia donde les sugería que se pusieran al amparo de la corona británica33.

5 Pero en la práctica, los pobladores civiles de Bayajá prefirieron por lo general quedarse en su sitio o trasladarse a Cuba en vez de jurar lealtad a Jorge III, Rey de Gran Bretaña. A principios de junio de 1796, varias embarcaciones, incluyendo la fragata española Minerva, se alistaban para recibir a bordo a las familias de Santo Domingo que buscaban salir hacia La Habana. Junto a los residentes españoles que huían iban también docenas de hombres y mujeres de Saint-Domingue que habían buscado protección bajo la bandera española durante los disturbios de la vecina colonia francesa ${ }^{4}$.

6 Entre los refugiados procedentes de Saint-Domingue que se aprestaban a abordar la Minerva estaba una joven llamada Françoise Lorignac Pomponne ${ }^{5}$. Miembros de la familia L'Aurignac (o Laurignac) habían sido dueños de tierra y esclavos en los distritos cafetaleros de Marmelade y Dondon, pero ahora los padres de Francisca estaban ausentes o muertos ${ }^{6}$. Françoise vivía en Bayajá con una prima llamada Isabelle de la Sablonnière. Los miembros de familias acomodadas que habían huido de la revolución y la abolición en Saint Domingue temían que Bayajá fuera entregada a fuerzas radicales alineadas con los franceses del otro lado de la frontera, incluyendo las tropas negras de Toussaint Louverture. Para Françoise Lorignac y su prima, evacuarse hacia la colonia esclavista de Cuba parecía el mejor camino a seguir ${ }^{7}$.

7 Marie Louise, amparado por su madrina, también buscaba irse de Bayajá, aunque por una razón diferente que más tarde explicaría: había quedado embarazada de un hombre blanco que había partido a La Habana y creía que si lograba llegar allí, el padre del bebé la ayudaría. Una amiga suya llamada Andrea le dijo que dos "señoritas" -Françoise Lorignac y su prima- iban a pagarle el pasaje a La Habana como su criada. Marie le pidió a Andrea que les rogara que la llevaran a ella también. Andrea prometió explicarle a Lorignac que se trataba de "una pobre conocida suya", asustada, y que el padre del bebé le reembolsaría el costo del pasaje una vez que el barco llegara a La Habana. De no ser así, Marie Louise trabajaría para Lorignac y se lo pagaría ella mismå.

8 Este cruce de una jurisdicción a otra atravesando el Paso de los Vientos abre la historia de Marie Louise/María Luisa Coleta como una indagación acerca de las dinámicas de libertad y esclavización ilícita en la diáspora de la Revolución Haitiana. Las autoridades de las colonias vecinas, a pesar de su hostilidad a esa revolución, no podían negar que decenas de miles de personas que habían estado esclavizadas ya no podían ser reclamadas como propiedad, y como personas libres podían partir hacia otras costas. Los registros judiciales, parroquiales y notariales que se reunieron a lo largo de la vida de María Coleta -y después de su muerte- permiten entrever el aprieto que pronto enfrentó como mujer inmigrante y como madre en la sociedad esclavista de Cuba. Estos fragmentos archivísticos, a su vez, dan indicios de los recursos espirituales y estratégicos que empleó en su búsqueda por asegurar la libertad de sus hijos9.

9 Antes de partir de Bayajá, Marie Louise y su amiga Andrea habían acordado lo que al parecer era un contrato tácito: Françoise Lorignac les organizaría el paso en la Minerva y ellas le pagarían en cuanto llegaran a Cuba. El trato se cerró entre personas aparentemente libres, dos mujeres negras jóvenes y vulnerables que estaban 
preparadas para desempeñar trabajo doméstico, y una joven blanca algo menos vulnerable proveniente de una familia de élite que se beneficiaría de ese trabajo. ¿Pero sería posible que ese contrato implícito de trabajo transmutara a las mujeres negras al estatus implícito de "esclavas"? Nadie sabía si la libertad declarada en Saint-Domingue sería reconocida como tal en otros lugares ${ }^{10}$. Las fuerzas republicanas que habían llegado a encarnar la soberanía francesa en toda La Española estaban ya publicando declaraciones de abolición que se extendían al antiguo territorio español de Santo Domingo. Pero incluso en la derrota, los gobernadores salientes de Santo Domingo no estaban preparados para aceptar tal concesión ${ }^{11}$.

Entonces, ¿en qué capacidad viajaron Marie Louise y Andrea a lo largo de las costas septentrionales de las islas de La Española y Cuba con Lorignac? Años más tarde, varios vecinos explicaron cómo recordaban estas circunstancias. Un testigo fue preguntado si Andrea y Marie Louise se habían unido a Lorignac y Sablonniere "agregadas en clase de criadas". Un hombre negro de Bayajá identificado como "peluquero" testificó que ambas viajaban "con el nombre de esclaba de ellas p[o]r no tener con que pagar el pasaje". Otro testigo recordó que se embarcaron "agregadas y a voz de esclavas", una frase idiosincrática que sugería dependencia y rumor del estatus de esclavo ${ }^{12}$. En efecto, su subordinación podría inferirse de la deferencia que mostraban frente a la autoridad de Lorignac, pero su estatus legal era imposible de determinar. Por el momento, sobrevivir en el presente seguramente parecía más urgente que futuras formalidades.

11 Cuando la Minerva entró en el puerto de La Habana en Junio de 1796, el gobernador Luis de las Casas se encontraba atrapado entre su obligación de admitir a las familias emigradas del Santo Domingo español, por una parte, y por la otra, su intensa aprensión acerca de los riesgos de permitir la entrada a negros presuntos testigos de, o participantes en, las insurrecciones de Saint-Domingue ${ }^{13}$. Las Casas les concedió pequeñas pensiones gubernamentales a las mujeres blancas Françoise (ahora Francisca) Lorignac y Isabelle (Isabel) Sablonnière, quienes se instalaron en la ciudad. Marie Louise y Andrea fueron detenidas en el Castillo del Morro en la boca del puerto, y quedaron inscritas en los registros de entrada de refugiados bajo la categoría "pardos y morenos libres"14. Marie Louise -ahora identificada como María Luisa- dio a luz durante su confinamiento en el Morro. Ocho meses después de su llegada, María Luisa y Andrea fueron entregadas a la persona considerada como su "dueño", es decir, a la familia de Francisca Lorignac ${ }^{15}$.

12 A lo largo de los veinte años siguientes, Francisca Lorignac combinaría el papel y la fuerza para trasladar a estas dos mujeres al estatus de esclavas, lo cual le permitiría reclamar a los hijos que tuvieron como propiedad. Las principales herramientas que Lorignac empleó fueron inscripciones hechas sobre papeles de carácter oficial: inscripciones en los registros sacramentales de una iglesia local e hipotecas registradas ante un notario, repitiendo siempre la palabra "esclava" como identificador después de sus nombres. Por décadas, María Luisa y Andrea, quienes carecían de pruebas escritas de su estatus de libres, no encontraron un camino viable para reclamar su libertad o la libertad de sus hijos de manera efectiva.

13 Para diciembre de 1816, la salud de María Luisa era delicada. Un fraile capuchino fue llamado a las habitaciones de los sirvientes de la casa de Lorignac, ubicada en el número 27 de la calle Amargura en La Habana, para escuchar su confesión y darle los últimos sacramentos. Ella comenzó su confesión de manera decidida, declarando ser la hija legítima de Sebastián y María Ambrosia, de la plantación Charmeraye en Saint- 
Domingue, comprada posteriormente por don Juan Pedro Poupet. Luego ofreció una detallada narración de su travesía, la cual implicaba también una travesía de su propio nombre, que ahora expresaba como 'María Coleta'16.

Escrita por una mano desconocida en papel grueso y sin sellos, la narrativa ha sobrevivido y reposa en el Archivo Nacional de Cuba entre los documentos reunidos por un notario público como parte de una demanda de libertad en nombre de las hijas de Andrea y María Coleta. A solo días de su muerte, María Coleta se las había arreglado para usar un acto sacramental para dar inicio a una demanda civil. En el proceso, creó un registro que permite entender, doscientos años después, cómo ocurrió su esclavización, cómo fue desafiada, y lo que su historia implica acerca de la naturaleza de la libertad en la era de la Revolución Haitiana ${ }^{17}$.

15 El hombre a quien María Coleta identificó como su antiguo amo, Pierre-Cyprien Poupet, resulta haber sido un comerciante expulsado de Luisiana en 1768 por conspirar contra la asunción de poder por España en ese territorio. Fue encarcelado en Cuba y posteriormente perdonado, después de lo cual se asentó en Saint-Domingue ${ }^{18}$. Con un hermano en La Rochelle y socios en Cap Français, Poupet se encargaba de las ventas de la mercancía de los barcos que transportaban cientos de africanos a la colonia ${ }^{19}$.

16 En junio de 1789, Poupet compró una hacienda conocida como la habitation Charmeraye. Limitada a un costado por el camino que iba del interior al puerto, y al otro por un río que desembocaba en la bahía en Cap Français, la plantación comprendía 130 hectáreas e incluía cañaverales, un molino de tracción animal y una casa de azúcar. Fue aquí donde Marie Louise/María Coleta había nacido en esclavitud bajo sus antiguos dueños. Vecina de la plantación Bréda (donde había nacido Toussaint Louverture) y de Petite Anse (un punto de reunión de los insurrectos Jean-François y Georges Biassou), la habitation de Poupet estaba cerca del centro de las acciones de agosto de 1791, cuando miles de hombres y mujeres esclavizados de la llanura del norte se alzaron contra sus $\operatorname{amos}^{20}$.

17 Ella debe haber tenido unos diez o doce años cuando los rebeldes incendiaron la plantación en el curso de la insurrección de agosto de 1791. Poupet siguió haciendo negocios en Cap-Français durante todo 1792 y parte de 1793, mientras los comisionados civiles franceses Léger-Félicité Sonthonax y Étienne Polverel exhortaban a las fuerzas locales a combatir a los insurgentes, que se habían reagrupado en las montañas ${ }^{21}$. Con la esperanza de impedir potenciales alianzas entre los insurgentes y los hombres y mujeres libres de color, Sonthonax y Polverel se empeñaron en hacer cumplir un decreto de París que les otorgaba derechos políticos a todos los hombres libres, con independencia de su color. Los comisionados creían que su estrategia era la única base segura para la continuación del dominio francés, mientras que los conservadores insistían en que tal estrategia era una imprudente amenaza a la estabilidad y la supremacía blanca. A medida que se abrían más fisuras entre los republicanos blancos, los realistas blancos y otros ciudadanos opuestos a los cambios en curso en la colonia, quedaba listo el escenario para un choque armado ${ }^{22}$.

18 En mayo de 1793 desembarcó en Cap Français François-Thomas Galbaud du Fort, el nuevo gobernador enviado por Francia para supervisar a los comisionados. La rivalidad personal y política, agravada por las complejas cuestiones de deudas y pagos, ahondaron la brecha entre los plantadores irritados, los comerciantes, y los comisionados. Los comisionados pronto ordenaron que se llevara escoltado al gobernador a un barco para devolverlo a Francia. Pero muchos marineros, oficiales 
navales y presos políticos franceses que se encontraban a bordo de diversos barcos anclados en la bahía compartían la hostilidad de Galbaud hacia las políticas que se asociaban a los comisionados Sonthonax y Polverel. Dos socios de la casa comercial de Poupet en Cap Français, Pierre Guymet y Pierre Gauvain, comenzaron a organizar la oposición blanca local a los comisionados civiles. El 19 de junio Galbaud se puso a la cabeza de una fuerza improvisada y desembarcó en la costa para contraatacar a las fuerzas que respaldaban a Sonthonax y Polverel. Al inicio se impusieron Galbaud y sus aliados, y obligaron a las fuerzas de los comisionados a retirarse a la plantación Bréda, cercana a la propiedad de Poupet $^{23}$.

19 Ante la perspectiva de una derrota, el comisionado Sonthonax hizo una movida desesperada y en buena medida imprevista: les prometió la libertad a los esclavos que se unieran a sus filas para atacar a las fuerzas de Galbaud. Algunos insurgentes negros y otros comenzaron a responder al llamado y las fuerzas combinadas repelieron a los atacantes hacia la ciudad. Galbaud y sus seguidores fueron presas del pánico, huyeron hacia los barcos que se encontraban en la bahía y partieron al exilio en los Estados Unidos. En las semanas siguientes, los comisionados, con el propósito de mantener unida su frágil coalición, emitieron una serie de decretos formales de emancipación, mediante los que liberaron primero a sus aliados inmediatos y después, sometidos a una presión continua, a todos los que en la colonia habían sido mantenidos en la esclavitud $^{24}$.

20 Poupet y sus socios Gauvain y Guymet, por el contrario, habían apostado al lado equivocado. Parece ser que Gauvain se alzó con el dinero de la compañía y se unió a los que escapaban de la isla. Un tiempo después reapareció en Filadelfia, rico y con historias que contar. ${ }^{25}$ Poupet, ya con más de sesenta años, parece haberse sentido totalmente desesperanzado. María Coleta diría más tarde que Poupet le había informado a quienes tenía esclavizados que iba a morir, y que a todos les daba su libertad ${ }^{26}$.

21 Si Poupet en realidad dijo que reconocía la libertad de los que habían sido esclavizados, ¿tenía la intención de que ello significara que manumitía a personas que todavía consideraba de su propiedad, o se trataba de un reconocimiento, hijo de la desesperanza, de la política general que siguió a la victoria de los comisionados civiles? ¿Estuvo Marie Louise, con once años, presente en lo que debió haber sido una escena dramática, o sus padres le explicaron con posterioridad que esa era la causa de que la familia se marchara de la plantación? Este recuento puede haber sido un caso de lo que los estudiosos llaman "posmemoria": sucesos contados a miembros de una generación más joven con tal fuerza emocional que estos los experimentan como si fueran recuerdos propios. Y por supuesto que podía ser simplemente una fabricación, no verificable décadas más tarde en otras tierras ${ }^{27}$.

22 Con el fin de la esclavitud, la muerte de su antiguo amo, y el colapso de la empresa de Poupet en la colonia, Coleta y su familia se convirtieron en refugiados internos indocumentados en una zona de guerra. Junto a los decretos de emancipación, los comisionados civiles estaban imponiendo regulaciones laborales draconianas que les exigían a los trabajadores agrícolas mantenerse en sus puestos y a los sirvientes domésticos que portaran "cartas de seguridad", documentos de identificación que especificaban quién era su empleador. Presumiblemente, la familia de Marie Louise carecía de esos documentos. Como ella lo describió más tarde, "empezamos a huir de la guerra y después de haber corrido todo llegó a regresar en Ballajá" 28 . 
Esta frase sugiere una hégira penosa a Fort-Dauphin/Bayajá por tierra. En los meses posteriores a la declaración de guerra de la monarquía española contra la Francia republicana a comienzos de 1793, la zona rural al este y al sur de Cap Français era un confuso rompecabezas de territorios en disputa. El rey de España había autorizado al gobernador de Santo Domingo a invitar refugiados de Saint-Domingue a convertirse en vasallos de la corona española, ofreciendo "el goce de la libertad" a aquellos que carecieran de ella e incorporando insurgentes negros a fuerzas de combate bajo la bandera española ${ }^{29}$. A mediados de 1793, un general español reportaba que Georges Biassou podía contar con alrededor de 16.000 seguidores armados de tales fuerzas: "Al oeste de Hincha por encima del Artibonito, empiezan los campamentos o palenques de Biassou que llegan hasta la Gran Rivière, o Río Grande frente de San Rafael y El Peñón". Es posible que una mujer joven en la situación de Marie Louise haya buscado abrigo con uno $u$ otro de los grupos que acampaban a lo largo y ancho del paisaje (Figura I) ${ }^{30}$.

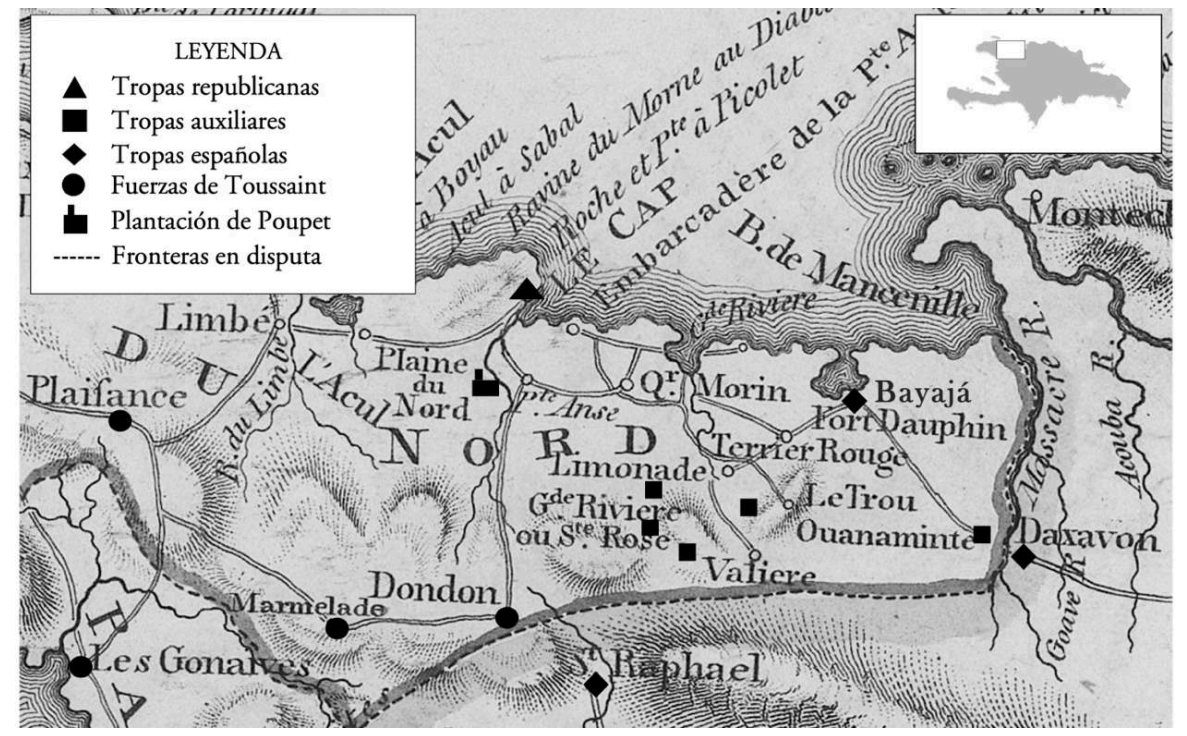

FIGURA I. La plantación de Poupet y la zona de guerra aledaña hacia el 12 de octubre de 1794. Las tropas auxiliares aliadas con España se hallaban estacionadas en al menos tres campamentos en cercanías de Grande Rivière. Las fuerzas de Toussaint Louverture, aliadas ahora con los republicanos, avanzaban hacia el este. San Rafael caería ante ellas para el 16 de octubre y Grande Rivière para diciembre. Por Ana María Silva Campo.

Adaptado de Carte de L'Isle St. Domingue dressée pour l'Ouvrage de M. L. E. Moreau de St. Méry Dessinée par I. Sonis, [Paris], 1796. Cortesía de la Biblioteca John Carter Brown en Brown University, https:// creativecommons.org/licenses/by-sa/4.0/. Los detalles del mapa provienen de las siguientes fuentes: Para Bayajá, ver Ada Ferrer, Freedom's Mirror: Cuba and Haiti in the Age of Revolution (New York, 2014), 110-12. Para Daxavon/Dajabón, ver Estevan Palomares al Marqués de Casa Calvo, Sept. 27, 1794, transcr. en Antonio del Monte y Tejada, Historia de Santo Domingo (Santo Domingo, 1890), 4: 274; Palomares a Casa Calvo, oct. 21, 1794, en Del Monte, Historia, 4: 288. Para Dondon, ver Juan Lleonart a Jean-François, oct. 12, 1794, en Del Monte, Historia, 4: 283-84; Ferrer, Freedom's Mirror, 96. Para Gonaïves, ver Ferrer, Freedom's Mirror, 115-17; David Patrick Geggus, Haitian Revolutionary Studies (Bloomington, Ind., 2002), 121-23. Para Grande Rivière, ver Lleonart a Jean-François, oct. 12, 1794, en Del Monte, Historia, 4: 283-84; Dubois, Avengers, 182. Para Le Cap (Cap Français), ver Geggus, Haitian Revolutionary Studies, 133. Para Marmelade, ver Ferrer, Freedom's Mirror, 115, 119; Lleonart a JeanFrançois, oct. 12, 1794, en Del Monte, Historia, 4: 283-84. Para Ouanaminthe/Juana Méndez, tomada por los españoles y sus aliados a finales de junio de 1793, ver Joaquín García a Gaspar de Cassasola julio 4, 1793, en Del Monte, Historia, 4: 54; Palomares a Casa Calvo, oct. 21, 1794, ibid., 4: 288. Para Plaisance, ver Ferrer, Freedom's Mirror, 119. Para Sainte Rose, ver "Le colonel Toussaint à Ste Rose", "Etat des Camps de la Grande Rivière", oct. 12, 1794, en Del Monte, Historia, 4: 284. Para San Rafael, ver Palomares a Casa Calvo, oct. 21, 1794, en Del Monte, Historia, 4: 287; [sin firma] a Palomares, oct. 22, 1794, en Del Monte, Historia, 4: 288; Ferrer, Freedom's Mirror, 141. Para la plantación azucarera de Poupet, ver René Phelipeau, Plan de la Plaine du Cap François en I'Isle St. Domingue, Paris, 1786, William L. Clements Library, University of Michigan. 

detenidos en la fortaleza del Morro. Después de cierto tiempo, Lorignac envió a un sobrino a la fortaleza para conseguir la liberación de ambas jóvenes. Según el recuento posterior de María Coleta, el sobrino le preguntó el nombre de su dueño. Ella negó tener dueño y le dijo que su amo había muerto por su propia mano para evitar que lo mataran y no había dejado herederos. Insistió en que antes de morir les había dicho que "ya los negros estaban levantados contra los que habían venido de Francia" y que, por tanto, "... a todos [sus esclavos] les daba la libertad porque iba a morir" 38 .

29 Entonces se redactó un documento al que Coleta llamó una "escritura". El expediente que ha llegado a nuestros días no incluye ese documento, pero en febrero de 1797 la "escritura" parece haber logrado que entregaran a Coleta y a su hijo recién nacido, así como a Andrea, a la custodia de Lorignac (o su sobrino), a quienes el registrador del 
gobierno describió entonces como su "dueño" ${ }^{39}$. Andrea y Coleta comenzaron a trabajar en el hogar de Lorignac, asumiendo que de esa manera pagaban la deuda por el pasaje en la Minerva. Sin embargo, no se había especificado un término de trabajo y había quedado implícito que ellas serían criadas domésticas sin pago.

En mayo de 1801 Coleta dio a luz a una niña. Pocos días después de su nacimiento, Lorignac la llevó a bautizar a la iglesia del Santo Ángel Custodio, ubicada en el cerro de la zona central de La Habana conocido como La Loma del Ángel (Figura II). El sacerdote inscribió a la niña como Inés Paula, hija de María Luisa morena, esclava de Doña María Francisca Lorignac. El registro bautismal -un documento estándar de identidad- ahora le imponía el término "esclava" tanto a la madre como a la hija, fortaleciendo el poder de Lorignac por medio de un documento que daba la apariencia de una pertenencia legal ${ }^{40}$.

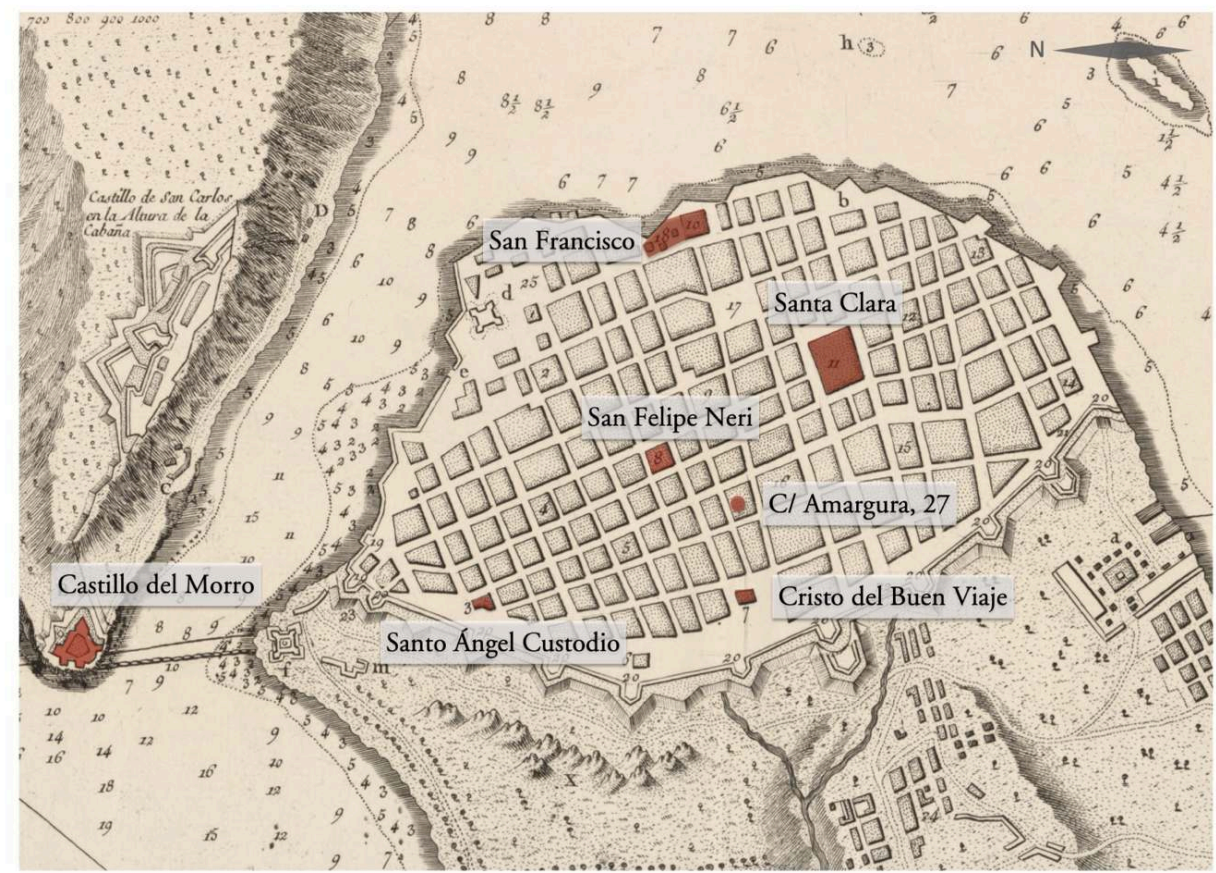

Figura II. A su llegada, María Luisa y Andrea fueron detenidas en el Castillo del Morro, en la entrada del puerto de La Habana. Más tarde trabajarían en casa de Francisca Lorignac, en el número 27 de la Calle Amargura, cerca de la residencia de los capuchinos en el Oratorio de San Felipe Neri. Mapa basado en Tomás López de Vargas Machuca, Plano de la ciudad y puerto de la Havana, [Madrid?], [1785?]. Library of Congress, Geography and Map Division. https://www.loc.gov/item/74690543/. Por Ana María Silva Campo.

En una tierra extranjera, viviendo bajo el techo de Lorignac con la carga de una deuda, habiendo trabajado durante cinco años bajo circunstancias que parecían implicar su sometimiento a esta pretensión de pertenencia, María Luisa aparentemente no veía una manera segura de retar su designación como propiedad de Lorignac. Ciertas huellas simbólicas relacionadas con su nombre y el de sus hijas sugieren una inclinación a la fe como fuente de esperanza en medio de su desamparo. La lista de refugiados en el momento de su encarcelamiento en el Morro había incluido el nombre de Marie Louise traducido al castellano simplemente como María Luisa. Pero en 1803 María Luisa acompañó a una segunda hija a la fuente bautismal en La Habana. En esta ocasión el 
nombre de la madre de la niña fue inscrito como Luisa Coleta, agregando el nombre de una santa a los nombres que había traído con ella desde Saint Domingue ${ }^{41}$.

La monja del siglo quince Colette de Corbie fue venerada como santa desde mucho antes de su canonización en 1807. En Lima colonial, una monja capuchina compuso una novena a Santa Coleta; las monjas capuchinas de Oaxaca patrocinaron la reimpresión de esas oraciones en 1795. Los devotos de Santa Coleta la consideraban especial protectora de las mujeres embarazadas, de las madres y de los niños ${ }^{42}$. En el siglo dieciocho, el convento de monjas de Santa Clara, segunda orden de los franciscanos, ya celebraba en La Habana una fiesta anual en su honor el cinco de marzo ${ }^{43}$.

33 ¿Había María Luisa decidido convertirse en María Luisa Coleta durante su embarazo, quizá durante un momento de oración frente a una imagen de Santa Coleta? La recién nacida también recibió un nombre devocional: María Loreto, referente a una de las advocaciones de la Virgen María, Nuestra Señora de Loreto. La fe y tal vez la súplica parecen haber cambiado la relación de María Luisa Coleta con su propio nombre y con los nombres de sus hijas. Su tercera hija, nacida en 1806, recibió un nombre devocional, María del Socorro, en referencia a Nuestra Señora del Perpetuo Socorro. Una hija que murió después se llamó Altagracia, referente a Nuestra Señora de Altagracia, patrona de Haití y Santo Domingo ${ }^{44}$.

34 Las leyes de las sociedades esclavistas en las Américas sostenían que un hijo nacido de madre esclavizada recibía el estatus de la madre y se convertía en propiedad del dueño de la madre. Los historiadores han identificado esta práctica como un componente crucial tanto de la lógica de género de la esclavización como de la apropiación racializada de niños como mero "aumento" ${ }^{45}$. El registro de Coleta y Andrea bajo el estatus de esclavas en las actas de la iglesia del Santo Ángel Custodio se basaba en una simple declaración de Lorignac, en presencia del sacerdote. Pero estas partidas de bautismo funcionaron en adelante como papeles de no-libertad, encerrando tanto a los niños como a sus madres bajo el estatus de propiedad negociable ${ }^{46}$.

35 Según su relato posterior, Coleta intentó reclamarle a Lorignac que era una mujer libre que había trabajado para ella más que suficiente para reembolsar el costo de su pasaje en la Minerva. Parece ser que le desafió a probar su titularidad: "que mostrase la escritura por donde me había comprado no la ha mostrado nunca". Pero todo fue inútil. Coleta siguió convencida de que era libre y de que sus hijos habían nacido libres, pero Lorignac no cedió ${ }^{47}$.

36 Algunos vecinos, incluidos otros refugiados de Saint Domingue y Santo Domingo, parecían pensar que la conducta de Lorignac con respecto a Coleta y Andrea era injusta. José Muños, un pintor procedente de Bayajá, instó a Lorignac a dejar que las mujeres gozaran de su libertad, y la antigua patrona de Coleta, Manuela Sainte, llegó a ofrecerle pagar la deuda por su transportación. Lorignac rechazó los requerimientos de ambos ${ }^{48}$.

37 Coleta estaba en un impasse. Huir de la casa con sus hijas y sin permiso probablemente la dejarían sin techo o la llevarían a la cárcel, solo para que después la obligaran a regresar y ser víctima de un duro castigo. Huir sola significaba separarse de sus hijas. Para apelar a un tribunal necesitaría obtener el apoyo de un síndico municipal, un procurador público especializado cuya tarea era oír las quejas y representar los intereses de los esclavos en cualquier procedimiento legal, a la vez que rechazar todos los reclamos inadecuados y mantener a los esclavos "bajo la debida sumisión" ${ }^{49}$. Era una posibilidad intimidante para una madre de niños pequeños sin papeles de libertad. 
Además, alegar que era libre con la acusación de esclavización ilegal significaba acusar a Lorignac de una conducta ilícita, lo que quebraba todos los entendidos o tratos implícitos que les proporcionaban un techo a Coleta y sus hijas. Pero mientras desafiar a Lorignac equivalía a correr el riesgo de un fracaso seguido de una represalia, Coleta también podía ver el creciente riesgo de que sus hijas -ahora en una edad en la que podían costar cientos de pesos cada una- fueran vendidas pronto ${ }^{50}$.

En efecto, la compra y venta de niños y jóvenes adultos se había convertido en parte del modus vivendi de Lorignac. Con conexiones a cultivadores de café al oeste de La Habana, Lorignac actuaba como un pequeño engranaje en la vasta maquinaria que transportaba cautivos africanos a la creciente economía de plantación cubana. Había esquivado la expulsión de los nacionales franceses en 1809 argumentando que era presuntamente española en virtud de su llegada desde Bayajá bajo la bandera de España, y por eso podía comerciar libremente en la ciudad ${ }^{51}$. En 1810 compró una niña de siete años identificada como mandinga, traída de la costa de África Occidental en el barco La Bella Gaditana. En algún momento compró a Josefa, mandinga, y a Rafaela, mandinga, y las vendió en 1811. Sin embargo, mantuvo a la niña de La Bella Gaditana, también llamada Josefa, hasta que cumplió catorce años, y en ese momento la vendió por más del doble del precio que había pagado por ella ${ }^{52}$.

En 1816, Inés Paula, la hija de Coleta, tenía quince años. Parece probable que Inés Paula, María Loreto, Monserrate, y María del Socorro hayan crecido junto a las jóvenes africanas, compartiendo el traspatio sin ventanas de la parte posterior de la casa 27 en la Calle Amargura. El riesgo de que las hijas de Coleta y Andrea fueran vendidas lejos de sus madres era totalmente claro.

Sin embargo, por la puerta del frente de esa misma casa, se veía cercana una posible fuente de autoridad contrarrestante ${ }^{53}$. La Calle Amargura, que corre desde la plaza de San Francisco hasta la iglesia del Cristo del Buen Viaje, formaba la ruta habitual de la procesión del Via Crucis, marcando las estaciones de la cruz. A dos cuadras se encontraba el Oratorio San Felipe Neri, donde se alojaban los miembros de la orden de los capuchinos. Cuando los otros sirvientes de la casa de Lorignac vieron que Coleta estaba gravemente enferma en diciembre de 1816, le dijeron que llamarían a un sacerdote para que le diera los últimos sacramentos. Coleta insistió en que sólo hablaría con el fraile capuchino Félix de Quintanar. Tanto ella como los demás sirvientes posiblemente conocían a los capuchinos como hombres que ministraban a los pobres y desposeídos ${ }^{54}$.

41 La orden de los capuchinos tenía una historia polémica e interrumpida en Cuba, cuyos orígenes se remontaban a la obra de los misioneros Epiphane de Moirans y Francisco José de Jaca en el siglo XVII. Jaca había pronunciado sermones en los que declaraba que la esclavitud era contraria a la voluntad divina, y se negaba a administrarles los sacramentos a dueños a menos que liberaran a sus siervos. Moirans escribió un volumen erudito en el que planteaba lo mismo. No resulta sorprendente entonces que las autoridades coloniales detuvieran a Moirans y Jaca y los enviaran a España para ser juzgados ${ }^{55}$. Un siglo después, en 1784, habían vuelto a Cuba capuchinos procedentes de España, y habían fundado un colegio para preparar a miembros de la orden para trabajar en la Luisiana y la Florida españolas. Fray Félix, originario de Quintanar, en España, parece haber sido mucho menos turbulento que sus predecesores del siglo XVII. Después de estudiar en La Habana, lo enviaron a Luisiana, y en 1796 ya se desempeñaba 
en una pequeña comunidad de canarios, colonos anglos, y africanos esclavizados llamada Galveztown, ubicada en las cercanías de Baton Rouge ${ }^{56}$.

42 Tratar de ejercer su ministerio entre los fieles y fundar una escuela en ese sitio apartado, lejos de Nueva Orleans río arriba, era un trabajo ingrato. Félix le escribió una carta plañidera al obispo en la que le decía que los dueños de esclavos de esa parroquia de Luisiana no le dejaban celebrar el sacramento del matrimonio entre esclavos. Los plantadores insistían en que no era necesario ningún sacramento. En tanto amos y dueños, creían que eran los únicos indicados para autorizar esas uniones. El obispo le respondió a Félix que debía seguir esforzándose, e instar a los miembros de su parroquia a que no se "casen los Negros ellos mismos, y les permitan venir a la Yglesia. .."57.

43 Tras varios años en el asentamiento de Galveztown, fray Félix fue reasignado a Nueva Orleans, donde asumió la tarea menos estresante de confesor de las monjas ursulinas de la ciudad. Cuando España le cedió la soberanía de Luisiana a Francia, y después Francia le vendió el territorio a los Estados Unidos en 1803, Félix partió de Luisiana para volver a reunirse con el minúsculo grupo de capuchinos que vivía en el Oratorio de San Felipe Neri en La Habana. Durante algún tiempo fungió como administrador principal de la orden, pero las inconvenientes peleas entre los hermanos le resultaron demasiado dificultosas y renunció al cargo en $1813^{58}$.

44 Cuando las compañeras de Coleta fueron a buscar a fray Félix en diciembre de 1816 lo llamaban para que realizara una tarea que de la que se encargaban con frecuencia los miembros de la orden de los capuchinos. A mediados del siglo XVIII, un oficial del ejército había dejado un donativo para que se les prestara asistencia espiritual a los agonizantes en la ciudad. La renta del donativo se le había otorgado a la orden de los capuchinos a su regreso a Cuba, lo que les confería la responsabilidad especial de proporcionar asistencia y oír la confesión de los moribundos de La Habana ${ }^{59}$.

45 Después de relatarle a fray Félix su historia de esclavización ilegítima, María Coleta se negó a recibir la absolución. En lugar de esperar la extremaunción, le pidió a fray Félix que registrara su "confesión" por escrito con el fin de presentarla ante un juez y dar inicio a una demanda de libertad en nombre de sus hijas y la hija de Andrea. Insistió en que sólo recibiría la absolución una vez que fray Félix hubiera cumplido con este deseo. Llevar el caso de sus hijas ante los tribunales se convirtió en una prioridad antes que su propia salvación espiritual ${ }^{60}$.

46 El proceso sacramental de la confesión se vio interrumpido, lo que puso a fray Félix en una situación incómoda. El secreto de la confesión estaba potencialmente en conflicto con su responsabilidad moral con Coleta (y, es de presumir, con la verdad y la justicia). Finalmente se llegó a una solución. Cuando regresó más tarde con un escribano, señalaron cuidadosamente que las palabras de Coleta habían sido pronunciadas bajo juramento, pero no bajo el sello de la confesión ${ }^{61}$. Cerca ya de la muerte, Coleta había encontrado finalmente una manera de ejercer su fuerza y una alianza a favor de sus hijas al pasarle a un eclesiástico una parte de la responsabilidad moral por la búsqueda de su libertad ${ }^{62}$.

47 La última "confesión" de Coleta delineaba un argumento que ella esperaba que se hiciera en nombre de sus hijas. Aún no podía reclamar el estatus de libre sobre la base de los decretos de abolición franceses en Saint-Domingue. Las autoridades cubanas nunca se considerarían obligadas a cumplir los estatutos de la Francia revolucionaria (o posteriormente Haití) sobre el explosivo tema de la esclavitud. Invocar los decretos de 
1793 emitidos por los comisionados civiles la habrían relacionado con sucesos revolucionarios ampliamente considerados en la época como emblemáticos del salvajismo. Por tanto, en su relato a fray Félix, Coleta enfatizó el peligro en el que había considerado que estaba, primero como una persona civil en un sangriento campo de batalla y luego como una mujer negra a punto de dar a luz al hijo de un hombre blanco en medio de lo que con frecuencia se consideraba una revolución racial. De manera crucial, ubicó su reclamo formal del estatus de libre en el pronunciamiento de su último dueño de que sus esclavos ya eran libres. En su versión, su estatus le había sido conferido por un acto generoso de su amo realizado justo antes de morir, mediante el cual había renunciado a la propiedad sobre su persona.

48 Su reclamo era entonces un reclamo equitativo basado en una petición para que el tribunal restaurara el buen orden de las cosas, que había sido violado por el comportamiento inmoral de Lorignac. Coleta enfatizó su buena fe al aceptar el pasaje en la Minerva y prometerle pagar con su trabajo la deuda en la que había incurrido. Su trabajo no remunerado no era, por tanto, señal del dominium de Lorignac -lo que indicaría que era de su propiedad- y mucho menos que sus hijas podían ser traspasadas como propiedades. Era una señal de que Coleta cumplía sus promesas. Ahora, con tanto trabajo realizado y la deuda seguramente pagada, buscaba el reconocimiento de que había sido libre durante todo ese tiempo. Coleta se presentaba como una mujer honesta que había sido objeto de una injusticia, no como una rebelde. Según su lógica, el estatus verdadero de mujer libre había venido con ella desde Saint-Domingue y, por tanto, se les transmitía a sus hijas desde el nacimiento, lo que contradecía la afirmación de Lorignac de que el ejercicio de su autoridad sobre ella era indicativo de posesión ${ }^{63}$.

49 Fray Félix accedió al pedido de ayuda de Coleta. En su opinión, Lorignac tenía a ella y sus hijos ilegalmente, porque "estos bienes eran usurpados" ${ }^{4}$. A primera vista, esta era una frase extraña que parecía sugerir que los derechos de propiedad sobre Coleta que alguien podía haber tenido (o aún podía tener) nunca habían sido legítimamente transferidos a Lorignac, quien era una mera espectadora y acreedora. Por tanto, la inscripción de las niñas por parte de Lorignac como sus esclavas podía verse como un fraude. Pero visto de otra manera, quizás el término "usurpados" fuera más radical. Las palabras de fray Félix tenían un eco de los peligrosos escritos de su predecesor capuchino Moirans, quien se había opuesto a la mayoría de los casos de esclavitud sobre la base de que ese derecho de propiedad usurpaba el derecho natural a la libertad de los africanos y sus descendientes ${ }^{65}$.

50 Aunque su afirmación general fuera potencialmente radical, los pasos iniciales de Félix fueron cautelosos. Se dirigió en persona a Lorignac que, evidentemente temerosa de un proceso legal, se mostró inicialmente de acuerdo y dijo que gustosamente dejaría en libertad a las niñas. Cuando fray Félix volvió junto al lecho de Coleta le informó sobre esa concesión, y le aseguró que si Lorignac no cumplía su promesa, iniciaría la acción legal. La cuestión estaba en buenas manos, le aseguró a la moribunda, y no debía seguir preocupada. Durante la tercera visita del fraile, ella hizo su confesión formal y aceptó la absolución ${ }^{66}$.

51 Las cuatro páginas de la narrativa de María Coleta a fray Félix no tienen la firma ni las iniciales de un notario, de modo que la transcripción de su confesión no fue un acto oficial. La fecha al inicio de la primera página es 19 de diciembre de 1816; la fecha al final de la última página es 13 de enero de 1817. Dos líneas horizontales dibujadas a lo ancho de las páginas sugieren que el documento se preparó en varios intervalos de 
tiempo. La letra, segura, no se parece a la trabajosa de fray Félix, que se puede ver en otros lugares; aparentemente, el fraile trajo consigo a alguien a la calle Amargura para que realizara la versión escrita ${ }^{67}$.

52 El documento comienza en un lenguaje semi-jurídico pero no del todo legal, enmarcado en la primera persona: "Siendo yo M[arí]a Coleta". Algunas de las afirmaciones atribuidas a Coleta suenan como respuestas a preguntas no llevadas al papel, como si los tres -la enferma, el fraile y el escribano -- sostuvieran una conversación a fin de producir una narración acordada. El documento abarca cuatro marcos temporales: la primera visita de fray Félix a Coleta, que incluye las conversaciones del fraile con otras sirvientas y la narración y súplica iniciales de la enferma; la segunda visita, durante la cual ella le pregunta al fraile si había hecho lo que le pidiera; la tercera visita, con su confesión y absolución formales; y por último una oración retrospectiva: "El día trece de enero de 1817 murió María Luisa Coleta"68.

53 Más tarde, en ese mismo día, un clérigo de la parroquia inscribió su muerte en el libro de sacramentos de la Iglesia del Santo Ángel Custodio: "Luisa Coleta morena criolla, hija de Ambrocio, y de Ana, escl ${ }^{\text {a }}$ de $D^{a}$ Franc $^{a}$ Lorignac reci[bió] [los] Santos Sacram ${ }^{\mathrm{s}}$ falleció como en la edad de treinta y cinco años. . ". Los detalles sobre los padres de Coleta (aunque trastocados) recuerdan los que ella le confiara a fray Félix, mientras que la porción final del registro, relativa a su estatus, sin duda provino de Lorignac. En lo que a los clérigos encargados de los libros tocaba, Coleta había nacido y había muerto esclava $^{69}$. Por el momento, entonces, la ficción de Lorignac de que era propietaria de la familia se mantenía en pie, y esta pronto se desdijo de su promesa de dejar en libertad a las niñas por su propia voluntad.

54 Una de las ventajas que podía reportar a un amo la esclavización de una mujer en un medio urbano era emplearla en oficios rentables o alquilarla a ese fin, como la venta diaria de productos comestibles en las calles, lavado de ropas, etc. Sin embargo, el terco rechazo de Lorignac a tratar a Coleta y Andrea como sirvientas libres no solo se derivaba del hábito y el deseo de no pagarles salarios, sino también de un hecho fundamental de la esclavitud: reclamar a una persona como propiedad podía ser un instrumento privilegiado para acumular más capital, sobre todo cuando el reclamo se hacía sobre una mujer en edad reproductiva ${ }^{70}$. Su exitosa afirmación de ser propietaria de las dos mujeres transformó a Coleta y Andrea, y más tarde a sus cuatro hijas sobrevivientes, en un tipo de propiedad formalmente llamada semoviente (capaz de moverse por sí misma), que podía emplearse como garantía colateral para un préstamo. Al quedarse en la Cuba esclavista, Lorignac había encontrado una manera de convertir a las personas que dependían de ella en capital y comenzar un proceso de acumulación que los refugiados que se habían ido a Francia no tenían a su alcance ${ }^{71}$.

55 No obstante, algunos de los vecinos habían comenzado a murmurar acerca de la injusticia cometida contra la familia de Coleta. Uno de esos vecinos era Ramona Jacoba, la viuda de un dirigente realista negro de la insurgencia de Saint-Domingue, Georges Biassou. El gobierno español, honrando incómodamente la promesa de protección hecha a los realistas negros que lucharan contra los republicanos en Saint-Domingue, había evacuado a Biassou y su familia de Santo Domingo a La Habana, y de allí a St. Augustine, en la Florida. Alegando problemas de salud, Jacoba había regresado desde allí a La Habana en 1799, y había recibido un estipendio del gobierno español por concepto de esposa y luego viuda de un oficial que había servido bajo la bandera española. Según su declaración décadas más tarde, conocía a Coleta de Saint-Domingue 
y sabía que era libre y al ver que Lorignac le había esclavizado, la había instado a "reclamar sus derechos"72.

56 Tras percatarse del riesgo de una denuncia durante su confrontación con fray Félix, Lorignac echó mano de más recursos del repertorio de poderes derivados de su supuesto derecho de propiedad sobre las hijas de Coleta. En marzo de 1818 recibió un préstamo de mil pesos de Luis Alejandro Sendrey, un piloto y en ocasiones capitán de barco. Como garantía de pago, presentó una hipoteca sobre las tres hijas de Coleta: Inés Paula, María Loreto y María del Socorro. Al emplear la hipoteca para obtener efectivo a partir de su valor como garantía colateral, le traspasó a su acreedor parte del riesgo planteado por el juicio de libertad ${ }^{73}$.

57 Cuando firmó ante notario el acuerdo de préstamo con Sendrey, Lorignac identificó a las tres niñas como nacidas en su hogar, hijas de la "esclava María Luisa", y como prueba mostró las partidas de bautismo. Algunos meses más tarde, a medida que la amenaza a partir de la declaración de Coleta en su lecho de muerte se hacía cada vez más clara, Lorignac renegoció la hipoteca con Sendrey. En el nuevo documento, se identificaba a las niñas simplemente como esclavas nacidas en su casa. Ahora Lorignac omitió en el papel la afirmación de que su propiedad se derivaba del estatus de Coleta, y la basó en el simple hecho de que las niñas habían nacido en un hogar sujeto a su autoridad $^{74}$.

58 Durante esos mismos meses, y quizás con el dinero del préstamo, Lorignac compró varios "bozales", esto es, africanos traídos del otro lado del Atlántico para venderlos como esclavos. En 1817 España había firmado un tratado con Gran Bretaña mediante el cual se comprometía a ponerle fin en 1820 al comercio atlántico de cautivos africanos llevados a Cuba. Lorignac y otros podían prever que el precio de esos cautivos aumentaría con el fin del comercio legal, lo que brindaba la posibilidad de una ganancia. Lorignac realizó algunas de estas compras a través de la casa comercial de Miró, Pie y Compañía. Aunque su pretendida esclavización de las hijas de Coleta se viera frustrada, seguiría disponiendo de capital invertido con seguridad sobre personas ya esclavizadas por los agentes de dicha compañía ${ }^{75}$.

59 Mientras tanto, fray Félix parece haber sentido incertidumbre acerca de qué hacer con el conocimiento y la narración escrita derivados de sus conversaciones con Coleta, e indecisión de cómo cumplir su promesa de velar por los intereses de las hijas. Aunque existían decretos reales que indicaban que en ciertas circunstancias los esclavizados podían presentar a un juez quejas por maltratos, en la Cuba de principios del siglo XIX los juristas frecuentemente argumentaron que los esclavizados no tenían la capacidad legal formal para llevar un caso a los tribunales o incluso para nombrar a un representante legal. De hecho, algunos planteaban que los esclavos carecían de personalidad jurídica básica y que, por tanto, no tenían derechos propios ${ }^{76}$. De existir un intermediario que representara sus intereses, debía ser designado por el estado. La persona adecuada no era un fraile capuchino, sino un funcionario municipal llamado síndico. Era él quien debía decidir darle o no forma legal a un reclamo planteado a favor de una persona tenida por esclava ${ }^{77}$. La práctica consuetudinaria, como lo han demostrado algunos historiadores, en ocasiones permitía que personas reclamadas como esclavas tuvieran acceso a los tribunales en sus propios nombres o por medio de amigos y patrocinadores ${ }^{78}$. Pero en La Habana, una demanda de libertad formal técnicamente requería la intervención del síndico ${ }^{79}$. 
60 Parece ser que fray Félix dejó pasar varios meses antes de visitar la oficina del síndico ubicada en la Plaza de Armas de La Habana. A juzgar por su correspondencia previa con el obispo sobre otros temas, a Félix no le gustaban los conflictos ${ }^{80}$. Puede que también estuviera consciente de su carencia de capacidad legal en el asunto y de la incomodidad de haber permitido que una cuasi-confesión quedara registrada en el papel. No obstante, en 1819 fray Félix ya le había llevado la declaración informal al síndico a fin de echar a andar el procedimiento legal, o se la había entregado a alguien que lo hizo ${ }^{81}$.

61 A la vez, el acreedor de Lorignac, Louis Alejandro Sendrey -quien viajaba a menudo entre los Estados Unidos y Cuba, aparentemente con un pasaporte estadounidense- se percató de que la garantía de su préstamo a Lorignac era la declaración de propiedad sobre unas personas que podía resultar falsa ${ }^{82}$. El 17 de noviembre de 1819 Sendrey presentó una demanda ante el Alcalde Ordinario del segundo distrito para intentar obligar a Lorignac a que le pagara la deuda, cuyo plazo había vencido hacía ocho meses $^{83}$.

62 Menos de una semana después, el 23 de noviembre, el síndico habanero Francisco Filomeno le entregó una petición al Alcalde Ordinario del primer distrito, un funcionario judicial, en la que le informaba que sus intentos de llegar a una solución negociada en lo relativo a la cuestión del estatus de las hijas de Coleta y Andrea habían fracasado debido a las evasiones y la intransigencia de Lorignac. El síndico Filomeno solicitaba formalmente una declaración de su libertad, y pagos atrasados de parte de Lorignac por el tiempo durante el cual había explotado su trabajo sin compensación. Sea cual fuere la visión general del síndico acerca de las demandas de libertad, parece que se había hartado de una ama putativa a quien posiblemente veía como una francesa poco colaboradora ${ }^{84}$.

63 Francisco Filomeno, quien se había hecho cargo del reclamo de libertad en noviembre de 1819, era un hombre nacido en circunstancias oscuras como hijo fuera de matrimonio de un rico aristócrata que al cabo del tiempo le reconoció legalmente y le dejó su título de marqués en herencia. Tras realizar estudios de leyes en La Habana, Francisco practicó el Derecho durante algunos años en España y después regresó a Cuba, donde se hizo famoso por su elocuencia, su sentido histriónico y su atractivo popular (en parte se hizo notorio al descubrir documentos escondidos en el baúl de un mensajero de quien se decía que estaba al servicio de José Bonaparte). A partir de los últimos meses de su período como síndico, empleó sus habilidades oratorias en la argumentación del caso de las hijas de Coleta y de Andrea ${ }^{85}$.

Filomeno informaba que a fin de evitar un litigio contra Lorignac había intentado concertar una reunión que produjera un acuerdo amigable. Sin embargo, Lorignac había negado el "estado" de las niñas, y se había negado a la "justa" solicitud hecha para "el reintegro de los derechos de que fueron despojadas sus madres". El abogado planteó el asunto como un caso de equidad centrado en los "derechos" de madres libres, y no en la capacidad legal de potenciales demandantes esclavizados. Describía la revolución haitiana como "desastrosa" y consideraba la ayuda de Lorignac con la compra del pasaje de Coleta y Andrea en la Minerva como un gesto moralmente necesario de auxilio a dos jóvenes en apuros, no un acuerdo contractual que pudiera acarrear un servicio por tiempo indefinido y mucho menos la esclavización. Ese planteo de la cuestión desplazaba la carga acusatoria de la prueba a Lorignac, al presionarla a mostrar un título válido u otra evidencia convincente de propiedad ${ }^{86}$. 
65 Tanto el síndico como Sendrey pronto se enteraron que Lorignac se había mudado con las hijas al poblado de Jesús del Monte, aproximadamente a una legua de la muralla. No obstante, cada vez que Sendrey pretendía que se le entregara allí la citación de los tribunales, sus sirvientes decían que no estaba. Puede que la casa de Jesús del Monte no haya sido su verdadero lugar de residencia sino supuesto, pero le resultaba útil, porque la ubicaba fuera de la jurisdicción directa de los tribunales y el síndico de la ciudad de La Habana, obligando así a que las citaciones pasaran por una serie adicional de funcionarios locales. Con una deuda de unos 6000 pesos y ahora amenazada con el desmontaje de su plan de convertir a personas libres en personas de su propiedad, Lorignac permanecía más o menos escondida, y se comunicaba con el tribunal por medio de intermediarios legales ${ }^{87}$.

66 Mientras tanto, la autoridad que presidía el litigio privado de Sendrey contra Lorignac había ordenado que las tres niñas hipotecadas se pusieran "en depósito" para asegurar los intereses del primero, acción que parece haberles hecho ver claro a las niñas el riesgo que corrían ${ }^{88}$. De hecho, a medida que se desarrollaba el proceso, las hijas de Coleta y Andrea empezaron a marcharse por su cuenta. A inicios de 1820, Lorignac se quejaba de que las niñas "se han ido todas separándose de mi abrigo, hasta tal extremo

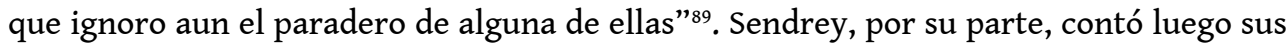
intentos de capturar a María del Socorro y la fuga de la muchacha de su custodia. Al final la ubicaron en la Casa de Beneficencia ${ }^{90}$.

67 El 17 de abril de 1820 llegaron a la Habana noticias de una súbita transformación en la metrópoli: como resultado de un golpe de estado supuestamente liberal, el rey se había visto obligado a jurar lealtad a la Constitución de 1812. España era ahora una monarquía constitucional. La "revolución liberal" trajo consigo un cambio de las autoridades municipales de La Habana, y la renuncia (o dimisión) de los funcionarios de la ciudad ${ }^{91}$. Un síndico recién electo, Mariano Hernández, junto a otro llamado Genaro Montoro, pronto se hizo cargo del juicio de libertad ${ }^{92}$. Hernández trató de anular las órdenes de depósito emitidas por el juez en el caso Sendrey e hizo sostenidas alusiones a que en la selección de los individuos a los cuales confiarles las niñas habían estado presentes diversas formas de connivencia y corrupción ${ }^{93}$.

68 Lorignac había logrado que se llegara a una especie de punto muerto: carecía de suficientes pruebas (o amigos bien ubicados) como para que se desestimara el juicio de libertad, pero había logrado ralentizar el proceso y evadir tanto a su acreedor como a los tribunales. Unos cuantos refugiados como ella estaban dispuestos a respaldar su historia de que había traído consigo a esas "esclavas", como "propiedades" que había salvado de la revolución haitiana. No obstante, estos testimonios vagos (y contradictorios, porque las hijas nacieron en Cuba) no eran suficiente para descaminar a los síndicos. La impaciencia de estos con Lorignac -una mujer nacida en el extranjero que desafiaba su autoridad y defraudaba a sus acreedores- parece haber mantenido el avance -aunque lento- del proceso ${ }^{94}$. El síndico Hernández produjo una larga serie de preguntas que debían planteárseles a los testigos dispuestos a declarar a favor de Coleta ${ }^{95}$. Lo detallado de los interrogatorios parece indicar que a esas alturas Hernández ya había conversado con refugiados de la barriada que conocían bien la historia. De octubre a diciembre de 1820 se les tomó declaración a varios testigos, y la evidencia contra Lorignac creció $^{96}$.

69 El caso avanzó muy lentamente durante el trienio liberal, los tres años de renovado constitucionalismo de la ley y la política español. El papel timbrado en que se escribían 
los documentos en La Habana llevaba ahora un recordatorio de que el rey le había jurado lealtad a la Constitución de 1812. Sin embargo, la adopción de estructuras constitucionales y la mayor libertad de expresión escrita no mejoraron la suerte de los esclavos en las colonias ${ }^{97}$. El régimen constitucional sí tuvo consecuencias potenciales para fray Félix, quien parece haber permanecido al margen del desarrollo del proceso. En octubre de 1820, el nuevo gobierno español ordenó la disolución de los conventos de las diversas órdenes religiosas ${ }^{98}$. El obispo de La Habana sugirió un tanto interesadamente que la desposesión debía comenzar por los capuchinos, a quienes consideraba una orden masculina pequeña y poco disciplinada que carecía de santidad y deferencia, ya que sus miembros andaban por la ciudad sin el debido acompañamiento ${ }^{99}$. Al final, la expulsión formal de los capuchinos no se llevó a cabo, pero fray Félix desaparece de la escena en los documentos. Puede que haya regresado a su natal España en busca de lo que años antes había descrito como la seductora "quietud de mi convento"100.

70 A fines de 1820 el tribunal también había tomado declaración a los testigos de Lorignac $^{101}$. Al inicio, el representante de Lorignac había presentado las copias de la inscripción de las partidas de bautismo como prueba del estatus de esclavas de las niñas. También había respondido a la posibilidad no expresada de que Coleta y Andrea pudieran haber sido liberadas por los decretos de las autoridades revolucionarias francesas, planteando que no podían haber sido beneficiadas por ellos, dado que su emigración se había producido "bajo la bandera española" ${ }^{102}$. Casi un cuarto de siglo después de la partida de La Española de la fragata Minerva, las dos partes volvían a litigar la cuestión de la esclavitud, el estatus y la revolución haitiana. Lorignac llevó a declarar a varios hombres de familias otrora prósperas cuyas declaraciones se inspiraron en la clásica imagen de los plantadores victimizados que habían huido de Saint-Domingue con unos pocos de sus "esclavos". El médico José Claret declaró que él, como Lorignac, había emigrado "con sus esclavos" que "fue lo único que pudo salvar en la revolución" ${ }^{\prime 103}$.

71 El punto clave de los interrogatorios promovidos por Lorignac descansaba en las preguntas sobre la duración y notoriedad de su posesión, para establecer que las hijas de Coleta y Andrea "han sido y son de mi única pertenencia, y bautizadas como tales". Se les pedía a los testigos si sabían que las "siervas" que se habían presentado eran de "mi absoluta propiedad desde mucho antes que se verificara la revolución en la Isla Española", y si "por ese dominio que tenía en esta las mandaba, y era ovedecida como su dueño". Quería que se le preguntara a cada testigo si "en todos tiempos las han reputado esclavas $m$ [ías] y si jamás han oido decir ayan salido por ningun título de la potestad Dominical" ${ }^{104}$. Ese era el centro del caso de Lorignac. Sin referirse a la manera en que había adquirido la supuesta propiedad de Coleta y Andrea, quería que su fait accompli de tratarlas como esclavas constituyera la evidencia de su propia legitimidad. Formaban parte de su hogar, en el cual ejercía lo que el derecho romano denominaba dominica potestas. Por eso, según ella, era evidente que tanto Coleta y Andrea como sus hijas le pertenecían.

Los interrogatorios preparados por el síndico a nombre de las niñas implicaban precisamente lo contrario: que en Bayajá siempre se había tenido a Coleta y Andrea por personas libres y, por tanto, eran libres. No obstante, explicar cómo esas dos mujeres de ascendencia africana habían obtenido su libertad en Saint-Domingue era un asunto delicado, dado que era mejor guardar silencio sobre los decretos revolucionarios 
franceses de abolición. En lugar de ello se invocaban múltiples posibilidades: los expedientes ya contenían la narración de Coleta a fray Félix en la que hablaba de una manumisión hecha por Poupet antes de su suicidio. El síndico -tal vez un poco confundido- preguntaba a Ramona Jacoba si la dueña anterior de Coleta, Mme. de la Charmeraye, ya le había concedido la libertad. En medio de todo ello se hacía referencia a la oferta de protección hecha a los refugiados por el gobierno español en los primeros meses de la guerra contra Francia, que parecía implicar una promesa de libertad ${ }^{105}$.

73 El argumento central seguía siendo de reputación y estatus social, en este caso, los de Coleta y Andrea en Bayajá veinticuatro años antes. Una vez establecida la reputación de libres, podía añadirse la evidencia de la desaprobación de los vecinos al ejercicio de la autoridad de Lorignac sobre ambas, y del intento de Lorignac de bautizar a las niñas para esclavizarlas. Las partidas de bautismo que Lorignac había confiado en que servirían como prueba socialmente reconocida de propiedad ahora parecían ser una evidencia de fraude y fuerza ilegítima. Manuela Sainte y Ramona Jacoba recordaron haber objetado la conducta de Lorignac. El pintor José Muños confirmó que en La Habana "habló a la Loriñak $\mathrm{p}^{\mathrm{r}}$. las citadas morenas a fin de $\mathrm{q}^{\mathrm{e}}$. las dejase gozar de su libertad" 106 .

74 Sorprendentemente, Isabel de la Sablonniére, la prima de Lorignac, testificó a favor de las hijas. Tras afirmar que había vivido con Lorignac en Bayajá, dijo que recordaba las circunstancias de su partida de modo muy distinto a su prima ${ }^{107}$. Andrea había trabajado para ellas en Bayajá, dijo Sablonnière, pero sabían que era libre y le pagaban un salario. A continuación, Sablonnière confirmó todos los hechos que los síndicos habían establecido contra Lorignac. Que pocos días antes de la partida del Minerva, Manuela Sainte les había llevado a Luisa Coleta a las primas para que se la llevaran consigo a La Habana como se estaban llevando a Andrea; que habían acordado llevar a las dos mujeres "con el nombre de sus esclavas" porque Coleta y Andrea no tenían dinero para pagar su pasaje; que a la llegada a La Habana Lorignac las retuvo como esclavas y bautizó a cada una de las niñas como esclavas. A Sablonnière -a quien evidentemente se había invitado a disociarse de las acciones de su prima- se le pidió entonces que mencionara los nombres de las hijas de Coleta para que todas pudieran reclamar su libertad. Finalmente, le preguntaron "si tenía ciencia cierta de $\mathrm{q}^{\mathrm{e}}$ las dos negras eran libres y como tales eran conocidas y tratadas en Ballajá, y si bajo este conocim $^{\text {to }}$ reconvino alguna vez a su prima $\mathrm{M}^{\text {me }}$ Lorignac". Su respuesta fue "sí"

75 En junio de 1821 Lorignac le extendió un poder a un nuevo agente que le pidió al tribunal los documentos del procedimiento y después desconoció las órdenes de devolverlos a tiempo, lo que impidió que el caso avanzara. La batalla por la custodia interina de las hijas continuó: Sendrey, Lorignac, el síndico, el custodio de la cárcel, varias familias de la localidad y un francés desconocido contendían por asumir su control. En defensa de su reclamo de custodia, Lorignac afirmó que, por supuesto, mantendría a las niñas disponibles en caso de ser requeridas por el juzgado, "tanto $\mathrm{p}^{\mathrm{r}}$ que esto es justo como porqe las quiero como que las he criado en mis brazos. .. " ${ }^{109}$. Al reclamo patriarcal de la dominica potestas agregaba ahora un reclamo matriarcal de afecto.

76 La primavera de 1822 encontró a María del Socorro, una de las hijas de Coleta, retenida en la Casa de Beneficencia, de la cual pidió que la dejaran salir por Semana Santa para reunirse con las otras tres niñas, que habían sido "depositadas" en el hogar de Da. Manuela Valdés. Al síndico le pareció una petición muy razonable, pero el juez decidió 
devolverle la custodia temporal de las cuatro hijas a Lorignac, a cambio del acuerdo de que su agente devolvería los papeles al tribunal para que el caso pudiera seguir adelante $^{110}$.

77 Cuando finalmente tuvo de vuelta el expediente del caso, el síndico Manuel Encinoso de Abreu intentó encargarse del asunto más agresivamente. A diferencia de la postura filantrópica de Francisco Filomeno, o de las acciones en cámara lenta de otros de sus predecesores, Encinoso asumió la posición de representante de individuos a quien incluso el juez ya describía como sus "clientes". Insistió en que le informaran dónde vivían en ese momento sus "defendidas," porque podría necesitar recibir de ellas alguna "instrucción". Además, no describió el procedimiento como un juicio de esclavos que buscaban su libertad, sino como un esfuerzo para negarle a Lorignac el dominium que había establecido sobre "cuatro infelices de condición libre". El caso siguió demorándose. No se pudo localizar a varios testigos de Lorignac para que reconfirmaran sus declaraciones, y Encinoso terminó su período como síndico sin que se llegara a una solución.

El nuevo síndico José Agustín Govantes, un abogado estudioso del derecho y profesor del Seminario de San Carlos y San Ambrosio, solicitó que se les diera a los testigos de Lorignac tres días para aparecer o el caso avanzaría directamente a su etapa final ${ }^{111}$.

79 Finalmente, en la primavera de 1823, Lorignac y su abogado se avinieron a un acuerdo. Si se eliminaba la demanda de pagos atrasados a las hijas, Lorignac renunciaría a su reclamo de propiedad. Govantes aceptó la propuesta. Pero al inicio el síndico no tenía idea de dónde se encontraban en ese momento las hijas, y se preguntaba si alguna habría muerto (parece ser que Francisco, el hijo de Coleta, al que no se nombró durante el juicio, había muerto poco después de que se iniciara el caso). Finalmente fueron localizadas bajo la custodia de dos mujeres de La Habana, Manuela Valdés y María Zubiera. Allí esperarían ahora que se emitiera un "auto de libertad" jurídicamente autorizado $^{112}$.

80 El procedimiento legal había terminado formalmente en una victoria para las hijas de Coleta y Andrea. Las cuatro jóvenes se presentaron en el tribunal para dar su consentimiento al acuerdo ${ }^{113}$. Inés Paula, la mayor, ahora con veintidós años, señaló que necesitaba que terminara el litigio para poder buscar trabajo con el cual mantenerse. La hija de Andrea y las dos hijas menores de Coleta no pudieron firmar y simplemente hicieron marcas señalando su consentimiento. Pero al firmar cuidadosamente su declaración, Inés Paula le añadió un apellido a su nombre de pila: Escovar. Quizás se había casado y adoptado el apellido del esposo. o tal vez hacía valer el apellido de su padre, tanto tiempo ignorado. En cualquier caso, con este acto borraba uno de los estigmas de la esclavitud: la ausencia de un apellido ${ }^{114}$.

81 No obstante, restaba un último trámite por completar. La identidad, la nacionalidad y el estatus se establecían convencionalmente mediante el examen de la partida de bautismo. Las de las hijas, permanentemente registradas en los libros de la iglesia del Santo Ángel Custodio, establecían que su estatus era el de esclavas. Los tribunales civiles tendrían que solicitarlo al obispo, y éste tendría que emitir una orden para que el sacerdote del Santo Ángel Custodio procediera a realizar el cambio en el margen del libro de bautismos, corrigiendo su estatus de "esclava" a "libre"115.

82 Los libros de bautismo permanecen en la Iglesia del Santo Ángel Custodio y son muy frágiles. Los custodios actuales de los libros, después de escuchar la historia de Coleta, se mostraron generosamente dispuestos a permitir el examen de los volúmenes 
originales. En las entradas correspondientes a los cuatro bautizos registrados, donde se esperaría encontrar las enmiendas al margen, estas no existen. Es posible que el párroco de la iglesia del Santo Ángel haya bloqueado el cambio para obedecer regulaciones dictadas por el obispado con anterioridad, o por no haber recibido alguna contribución exigida por hacer estas anotaciones. De todas formas, no se anotó nada que indicara que la palabra "esclava" no debía tomarse en lo adelante como una indicación del estatus de las hijas. Como documentos de identidad, entonces, las partidas de bautismo mantuvieron latente el riesgo de re-esclavización ${ }^{116}$.

Sin embargo, es muy probable que la hijas hayan recibido las copias de la sentencia del tribunal que establecía que eran libres, una para cada una. El escribano se había negado a entregarlas porque ellas carecían de recursos para pagarle, pero el juez ordenó lo hiciera de todas formas y se les dio plazo de un mes para pagar esas escrituras. El expediente no indica si dicho pago fue realizado finalmente transcurrido el mes ${ }^{117}$.

84 Lenta e inciertamente, el caso se había arrastrado pesadamente por los tribunales cubanos, año tras año, mientras Lorignac y sus agentes emprendían una maniobra dilatoria tras otra, frente a uno tras otro síndico. En Cuba, como en todo el resto de las Américas, la institución de la esclavitud estaba enmarcada por la ley, y la fuerza coercitiva del amo tenía el respaldo de la regulación municipal, estatal y federal o imperial. La institución del síndico le proporcionaba un acceso limitado y mediado a la ley a una reducida minoría de los designados como esclavos. Pero la situación de hombres y mujeres que, como Coleta, eran tenidos como esclavos en ausencia de un título legal, subraya una contradicción medular que subyacía a esa legalidad.

85 Las leyes sobre la esclavitud se basaban en la presunción de que podía tenerse a ciertas personas en propiedad, pero no ofrecía una información coherente sobre cómo discernir ese estatus más allá de una presunción de fondo, en la que incidía aunque no definía por completo, una diferencia en el color percibido de la piel. Se requerían documentos para derrotar la presunción del estatus de esclavo, pero rara vez para mantenerlo.

$86 \mathrm{Al}$ abordar la fragata Minerva, Coleta y Andrea se escurrieron con la categoría de criada (o tal vez incluso de esclava) dentro de un núcleo familiar de refugiados (presumiblemente blancos) cuyo viaje a Cuba se había aprobado. Pero a los pocos días se vieron atrapadas por la resistencia del gobernador a permitir la entrada de refugiados negros -esclavos o libres- en La Habana. Para Coleta, la presunción del estatus de esclava se reforzaba cuando la liberaran de la fortaleza del Morro, para transferirla a su "dueño". A partir de ese momento, se multiplicaron las señales que la marcaban como una persona que era propiedad de otra, haciéndole imposible escapar del peso del servicio a Lorignac, y permitiéndole a esta que bautizara a sus hijas como esclavas.

87 El expediente del proceso legal iniciado en nombre de las hijas de Coleta puede verse como un inventario de los sucesos que debieron converger para que se produjera al menos algo parecido a una reparación. Primero, los amigos y compañeros refugiados con ella estuvieron dispuestos a declarar sobre su recuerdo compartido de la libertad legal que esta había portado consigo desde 1793 hasta la última noche que permaneciera en el hogar de su madrina en Bayajá en 1796. Veinticuatro años después, cuando se les llamó a responder a las preguntas del síndico, esos testigos mantuvieron la discreción sobre los sucesos que habían echado por tierra la ley de la esclavitud en Saint-Domingue, pero firmes en cuanto a sus consecuencias para Coleta ${ }^{118}$. 
88 El segundo golpe de suerte fue la presencia en La Habana de un minúsculo grupo de capuchinos que vivían cercanos a la casa de Francisca Lorignac. Aunque el obispo desconfiaba de ellos, mantenían una modesta práctica pastoral en la comunidad, en especial la oferta del servicio religioso de la extremaunción. Si Coleta hubiera vivido en una comunidad rural le habría resultado mucho más difícil identificar a un potencial aliado clerical. Pero en el centro de la ciudad existía la posibilidad de esa alianza. Durante sus largos años de esclavización, había aprendido a no confiar en el sacerdote de la iglesia del Santo Ángel Custodio, y les pidió a sus amigas que buscaran a fray Félix.

89 El tercer factor fue institucional, derivado de la existencia del cargo de síndico procurador, la peregrina solución administrativa empleada en Cuba para las complejidades derivadas de haber definido a las personas esclavizadas como carentes de capacidad legal. Un síndico podía sentir o no simpatía por el tema, pero su tarea consistía en sostener -y vigilar- el estrecho canal que podía conducir a un procedimiento legal limitado. Los sucesivos síndicos que se ocuparon del caso de las hijas de Coleta y Andrea estaban muy involucrados en las luchas legales y políticas más generales de la época. De ahí que sus intervenciones reflejaran las variantes de conservadurismo, reformismo y discreto liberalismo de los profesionales de la ciudad capital, así como las rivalidades individuales endémicas en la profesión legal. En resumen, la existencia del síndico no garantizaba el acceso a la ley, pero una vez que un caso estaba en manos de un síndico ambicioso, podía verse influido por la mezcla de principios y posturas que caracterizaban la política de la época ${ }^{119}$.

90 A Francisco Filomeno, quien dio los primeros pasos formales en noviembre de 1819, el caso le dio la oportunidad de adoptar una pose histriónica. Su demanda en nombre de las hijas de Coleta y Andrea evocaba los peligros de la "desastrosa" revolución ocurrida en Saint-Domingue e invocaba el deber de compasión que debía haber conducido a Lorignac a ayudar a esas infortunadas jóvenes en su huida. Con ese abordaje, Filomeno alzaba el tono, pero disminuía la apuesta, al alejarse de todo reclamo general en nombre de quienes habían alcanzado su libertad legal durante la revolución haitiana, y mezclando los llamados al sentimiento con una referencia a los "derechos" de los que las madres de las niñas habían sido "despojadas"120.

91 Los sucesores de Filomeno siguieron sus pasos con grados diversos de energía. El síndico interino Genaro Montoto parece haberle dado al caso un empujón extra, y su colega constitucionalista Mariano Hernández lo hizo avanzar hasta la etapa de pruebas. A partir de ese momento el caso se estancó de nuevo, dado que los representantes de Lorignac se negaron a responder, mantuvieron en su poder dossiers que debían haber devuelto y, en líneas generales, crearon ruidos legales y retóricos para ralentizar las cosas. No obstante, finalmente, cansando a Lorignac, enfrentando los ardides de su agente y eliminando la demanda de pagos atrasados, los últimos síndicos lograron un acuerdo por mutuo consentimiento que reconocía la libertad de Inés Paula, María del Socorro, María Monserrate y María Loreto. La arriesgada apuesta de Coleta desde su lecho de muerte le había permitido a sus hijas captar la atención de la ley. Sin embargo, deshacer las arraigadas suposiciones acerca del estatus requirió de una ayuda tras otra por parte de varios testigos, y múltiples golpes de buena fortuna.

92 La historia de María Luisa Coleta refracta múltiples vidas vividas entre imperios: las de Coleta, su amiga Andrea, su némesis Francisca Lorignac, el fatigado fray Félix y los muchos refugiados de Saint-Domingue que recordaban distintas dimensiones de la revolución haitiana. A diferencia de las vidas itinerantes de ágiles personas 
cosmopolitas a partir de las cuales los historiadores han creado microhistorias globales, la vida de Coleta consistió en una situación insoluble tras otra ${ }^{121}$. Desde que llegó a La Habana en 1796, los obstáculos en su contra eran casi imposiblemente grandes. No le dio la bienvenida el ansiado padre de su hijo, sino un gobernador intransigente decidido a detenerla, y después el plan de Lorignac para pasarla de la detención por el estado al trabajo esclavo en su hogar.

93 Coleta no encontró un camino llano de acceso a la justicia, una estrategia evidente mediante la cual ejercer su agencia para abrir pequeñas fisuras en la ley. Aunque algunos de sus amigos la instaron a reclamar sus derechos, fue solo cuando enfrentó la muerte y el futuro día del juicio que encontró un camino. Podía utilizar visible, conspicua e instrumentalmente el momento de la confesión para pasarle parte de su fardo moral a los hombros cansados de fray Félix, obligándolo a transformar sus palabras en una declaración que pusiera la ley en movimiento.

94 La reparación legal resultó lenta, y el subsiguiente fracaso de los tribunales y la iglesia para corregir el registro sacramental dejó a las hijas de Coleta y Andrea potencialmente vulnerables a la explotación y la manipulación. Además, la liberación formal de esas cuatro jóvenes de la demanda de propiedad de Lorignac no estableció un precedente para otros en situación similar. No obstante, al mirar atrás, el éxito del procedimiento legal revela uno de los efectos duraderos de la revolución haitiana. Al provocar una ruptura en las relaciones de propiedad de las que dependía el estatus de esclavo, la revolución produjo un quiebre visible en toda supuesta cadena de título. Aunque los supuestos amos actuaban como si su derecho de propiedad hubiera sido simplemente suspendido, no cancelado, todo intento de retrotraer a un refugiado a la categoría de esclavo podía potencialmente revelar el ejercicio de fuerza y coerción sobre el que, en última instancia, se basaban los reclamos de la propiedad sobre personas. Las palabras de la confesión de Coleta y la subsiguiente acción legal -la tinta llevada al papel por el escribano del fraile, el notario, los síndicos, los amanuenses y el juez- dieron origen a un registro escrito de las maniobras llevadas a cabo por Francisca Lorignac y sus aliados. Lorignac había confiado en que la presunción y la actuación crearan una apariencia de posesión, que sabía que después la ley interpretaría como propiedad ${ }^{122}$. El sacerdote de la parroquia del Santo Ángel Custodio contribuyó, consciente o inconscientemente, a perpetuar la ficción mediante las partidas de bautismo. Pero al final, Coleta, superando por un momento la vulnerabilidad inherente a su situación, se volvió hacia fray Félix para que la ayudara a revelar la usurpación. En el último momento Coleta ya no fue "agregada y a voz de esclava". Había encontrado una voz diferente y una manera de confiarla al papel para que todos la oyeran.

\section{NOTAS}

1. Para el itinerario de María Coleta, véase "El Síndico del Exmo Ayuntamiento, ctra Doña Franc[isc]a Loriñak, sobre la libertad de sus cuatro esclavos nombrados Inés Paula, M[arí]a del Socorro, María Montserrate y M[arí]a Loreto," Expediente (Exp.) 2100, Escribanía de Bernardo del Junco, Legajo (Leg.) 141, Archivo Nacional de Cuba (ANC), La Habana. Abreviamos este expediente 
como "Síndico contra Loriñak". Hemos mantenido la ortografía original entre comillas, pero hemos agregado tildes cuando ha sido necesario.

2. Ver Gordon Forbes a Henry Dundas, 6 de enero de 1796, 16-17, en Santo Domingo, Governors' Dispatches, Vol. II, WO 1/65, The National Archives of the United Kingdom (TNA-Kew); y el parte de un informante encabezado "Du Fort Dauphin le 12 à six heures du matin", también en WO $1 / 65$. El recuento definitivo sobre la presencia británica en Saint-Domingue durante esos años es el de David P. Geggus, Slavery, War, and Revolution. The British Occupation of Saint Domingue, 1793-1798 (Oxford: Clarendon Press, 1982).

3. Sobre las negociaciones -finalmente fracasadas- entre emisarios de los británicos y los miembros restantes del "ejército de Jean-François", ver la correspondencia del gobernador británico Sir Adam Williamson y el mayor general Gordon Forbes con autoridades de Gran Bretaña, en WO 1/65 y en CO 245/3, TNA-Kew; y en Add. MS 39824, Letter.Book of Maj.-Gen. Gordon Gorbes en la British Library (BL).

4. Se puede encontrar correspondencia oficial española sobre estos refugiados de SaintDomingue en Exp. 113, Leg. 5B, Estado, Archivo General de Indias, Sevilla, disponible en forma digital en PARES (pares.mcu.es).

5. En una copia de la lista de pasajeros que se registró en La Habana aparece como " $D[0 \tilde{n}] \mathrm{a}$. Francisca Lorinac Ponpon". Un fragmento de esta lista de pasajeros está incluida en "Francisca Lorignac solicita se le conceda licencia para vender una negra," 1813, Exp. 16, Leg. 187, Escribanía del Gobierno, ANC. En un registro de las familias que llegaban fue identificada como "Madama Pompone, soltera, nat[ura]l del Dondon, de 19 años". "Segunda Lista de los Asientos correspondientes a las familias de S[an]to Domingo, Vale des[de] 23 de Junio de 1796," Exp. 2, Leg. 252, Fondo Asuntos Políticos (AP), ANC.

6. Los registros sacramentales de Dondon, que se conservan en los Archives Nationales d'OutreMer, en Aix-en-Provence (ANOM) y están disponibles vía IREL (anom.archivesnationales.culture.gouv.fr), muestran la firma de Sieur L. Auringac en Baptême de Rose, 15 de noviembre de 1778, ANOM, État Civil, Saint-Domingue, Paroisse du Dondon, Ressort du Cap, 1778, Folio 22. Una propiedad que se designa como perteneciente a "Laurignac", probablemente un cafetal, aparece al pie de las alturas cercanas a Marmelade en un mapa de 1760: Carte topographique de la région du CapFrançais et du FortDauphin, au Nordest de la colonie française ou St. Domingue. Le agradecemos a John Garrigus habernos indicado esta propiedad.

7. Sobre las complejidades de la situación en Bayajá, véase Ada Ferrer, Freedom's Mirror. Cuba and Haiti in the Age of Revolution (Nueva York: Cambridge University Press, 2014), 83-145; y el reporte, aparentemente de mayo de 1796, titulado "Du Fort Dauphin le 12 à six heures du matin", Santo Domingo, Governor's Dispatches. vol. 2, pp. 807-10, WO 1/65, NAUK.

8. "Síndico contra Lorignac," fol. 3r. Marie Louise/ María Coleta también afirmó más tarde que le había pedido a Andrea que le dijera a Lorignac y Sablonnière que buscaba irse "para no ocasionar que le quitasen la vida por estar embarazada de blanco". "Síndico contra Loriñak", folios 3r-3v.

9. Sobre cuestiones de estátus y migración, véase Sue Peabody, “'Free Upon Higher Ground': Saint-Domingue Slaves' Suits for Freedom in U.S. Courts, 1792-1830", en The World of the Haitian Revolution, ed. David Patrick Geggus y Norman Fiering (Bloomington, Ind., 2009), 261-83; Martha S. Jones, "Time, Space, and Jurisdiction in Atlantic World Slavery: The Volunbrun Household in Gradual Emancipation New York", Law and History Review 29, no. 4 (noviembre 2011): 1031-60; Rebecca J. Scott y Jean M. Hébrard, Papeles de libertad: una odisea transatlántica en la era de la emancipación, traducido por Esther Pérez Pérez (Bogotá: Universidad de Los Andes; Instituto Colombiano de Antropología e Historia, 2015; y La Habana: Editorial Unión, 2014) caps. 2-3; Ada Ferrer, "Haiti, Free Soil and Antislavery in the Revolutionary Atlantic", American Historical Review 117, no. 1 (febrero 2012): 40-66; Scott, "Social Facts, Legal Fictions, and the Attribution of Slave Status: The Puzzle of Prescription”, Law and History Review 35, no. 1 (enero 2017): 9-30. 
10. Véase David P. Geggus, ed., The Impact of the Haitian Revolution in the Atlantic World (Columbia, S.C., 2001); Geggus y Fiering, World of the Haitian Revolution; Sara E. Johnson, The Fear of French Negroes: Transcolonial Collaboration in the Revolutionary Americas (Berkeley, Calif., 2012); Ferrer, Freedom's Mirror; Julius S. Scott, El viento común: corrientes afroamericanas en la era de la Revolución haitiana (Madrid: Traficantes de Sueños, 2021).

11. Véase Exp. 1, Leg. 3407, Estado, AHN; Gordon Forbes a Henry Dundas, ene. 7, 1796, fol. 8r, Letterbook of Maj.-Gen. Gordon Forbes, Add. MSS 39824, BL. Para un período posterior, véase María Cecilia Ulrickson, "Cultivators, Domestics, and Slaves: Slavery in Santo Domingo under Louverture and Napoleon, 1801-1803", Americas 76, no. 2 (abril 2019): 241-66.

12. Véanse los interrogatorios del demandante en "Síndico contra Loriñak", fols. 25r-27v ("agregadas," 25v), y las deposiciones de los testigos, ibid., fols. 104r-112r. La frase "con la familia de Madama Loriñac bajo el nombre de esclaba de ellas p[o]r no tener con que pagar el pasaje" aparece en el testimonio de Francisco Vluc [Puech?], ibid., fols. 109r ("peluquero") y 109v (cita). La construcción “a voz de esclavas" está en el testimonio de D. José Muños, ibid., fol. 111v.

13. Cuatro meses antes, Las Casas había emitido un bando que prohibía rotundamente la entrada a personas de ascendencia africana libres o esclavizadas provenientes de Saint-Domingue: "Bando dictado de la Habana el 25 de Febrero de 1796. . . sobre reglamentación para la introducción de negros esclavos, etc.”, Exp. 26, Leg. 255, AP, ANC.

14. Véanse las entradas para María Luisa y (María) Andrea [inscrita como "Mariquita"] en "Segunda lista", folios 136r y 159r.

15. La fecha de su salida del Morro aparece en "Segunda lista", folio 136r.

16. Véanse los folios $3 \mathrm{r}, 3 \mathrm{v}, 4 \mathrm{r}$ y $4 \mathrm{v}$ de "Síndico contra Loriñak". Por razones que se explican más adelante, creemos que agregó "Coleta" a su nombre bautismal algunos años después de su llegada a la Habana, probablemente hacia 1803. Hemos intentado alinear nuestro uso de nombres con esta cronología, refiriéndonos a ella como Marie Louise/María Luisa antes de 1803, y como María Coleta, o Coleta, después de esa fecha.

17. Abreviamos las citaciones del documento al que el escribano se refirió como una secuencia de confesiones por parte de Coleta, comprendidas en los folios $3 \mathrm{r}, 3 \mathrm{v}, 4 \mathrm{r}$ y $4 \mathrm{v}$ del expediente, como CC, "Síndico contra Loriñak".

18. Ver Gilbert C. Din y John E. Harkins, New Orleans Cabildo: Colonial Louisiana's First City Government, 1769-1803, 44n14, 49; Emilie Leumas, “Ties that Bind: The Family, Social, and Business Associations of the Insurrectionists of 1768", Louisiana History: The Journal of the Louisiana Historical Association 47 (Primavera, 2006): 183-202; y Danielle Miet, "Evolution économique et sociale d'une famille rochelaise au XVIIIe siècle. La famille Poupet”, Mémoire de Maîtrise, Université de Poitiers, U. E. R. des Sciences Humaines, 1982.

19. Ver, por ejemplo, Affiches Américaines (Cap Français), 3 de marzo de 1784, para un anuncio de la llegada del Belle-Pauline, procedente de St. Malo, con 568 cautivos de la costa de Angola a ser vendidos por MM. Poupet frères \& Compagnie.

20. Ubicado en la Rivière du Haut du Cap, el terreno está marcado "Hér[itier]s la Charmeraye" en el mapa de René Phelipeau, Plan de la Plaine du Cap François en l'Isle St. Domingue, Paris 1786, www.loc.gov/item/73695940/. Sobre los daños a la plantación y sobre el levantamiento en general, ver Archives de Gallifet, Biens à St. Domingue, 1771-1804, 107 AP/128, Archives nationales, Pierrefitte-sur-Seine (ANP), Francia; La Dame La Saudraye v. C. Poupet, 13 Fructidor An 10, Tribunal d'Appel, séant à Poitiers, decisión publicada en Jean-Baptiste Sirey, Recueil général des lois et des arrêts, en matière civile, criminelle, commerciale et de droit public, depuis l'avènement de Napoléon, vol. 2 (Paris, ca. 1803?), 230-40, la sección titulada "Lois et Décisions diverses"; Laurent Dubois, Avengers of the New World: The Story of the Haitian Revolution (Cambridge, MA: Harvard University Press, 2004) 92-100. Una carta solicitando indemnización enviada por el hermano de Poupet contiene una descripción detallada de la propiedad: Dossier P-351, Poupet (P[ier]re Cyprien), Indemnité St. Domingue, Dossiers Traités, 7SUPSDOM/78, ANOM. 
21. Ver el informe de inspección de fecha 7 Brumaire An 8 [oct. 29, 1979], reproducido en Dossier P-351, Poupet (P[ier]re Cyprien), Indemnité Saint-Domingue, Dossiers Traités, , 7SUPSDOM/78, ANOM.

22. Ver la introducción a David Geggus, ed., The Haitian Revolution: A Documentary History (Indianapolis: Hackett Publishing Company, 2014), xi-xxxiv. Le agradecemos a Manuel Covo su explicación sobre las políticas de los comisionados relativas al pago de alimentos llevados a Cap Français en barcos norteamericanos, que, a su vez, trastornaron las compras de los transportados por barcos mercantes franceses. Manuel Covo, comunicación personal, junio de 2018.

23. Ver Jeremy D. Popkin, You Are All Free: The Haitian Revolution and the Abolition of Slavery (Nueva York, 2010), 155-245; Manuel Covo, "Commerce, empire er révolutions dans le monde atlantique: La colonie française de Saint-Domingue entre métropole et États-Unis (ca. 1778-ca.1804)”, Ph.D. diss. École de Hautes Études en Sciences Sociales, Paris, 2013). Ver también la correspondencia enviada al Comité des Colonies por J. F. Moissonier, incluyendo el documento titulado "Liste des habitants de St.-Domingue qui conspirent contre la République française dans les États-Unis de l'Amérique", en item 7, Dossier 59, D/XXV/6, ANP. Moissonier reportó que Pierre Guymet y Pierre Gauvin habían sido "los instigadores y cómplices de Galbeau en el asunto de 20 en Cap [Français]; marcharon a la cabeza de los marineros y los blancos de su partido" (ibid.). Guymet estaba casado con la media hermana de Pierre-Cyprien Poupet, mientras que Gauvain era socio de Poupet y, según Moissonier, se rumoreaba que era hijo ilegítimo de Poupet ("le fils du postier").

24. Popkin, You Are All Free, señala la incertidumbre acerca del momento preciso en que se produjo la decisión de los comisionados de hacer un llamado a los esclavos.

25. La posterior solicitud de indemnización presentada en Francia por el heredero de Pierre Cyprien Poupet hacía referencia al supuesto robo de Gauvain. Ver Dossier P-351, Poupet (Pre Cyprien), Indemnité Saint-Domingue, Dossiers Traités, 7SUPSDOM/78, ANOM.

26. Coleta insistió en que "todos sabían" que después de esto Poupet se había envenenado, prefiriendo la muerte por su propia mano que la muerte que le darían los insurgentes. CC, "Síndico contra Loriñak", fols. 3r, 3v.

27. Una carta escrita por Pierre Gauvin daba cuenta de que Poupet había muerto en Cap Français en junio de 1793, de un "coup de sang" (un derrame cerebral). Ver el análisis de esa carta (de Pierre Gauvain a Michel Poupet, de fecha 20 de mayo de 1796) en Miet, "Evolution", p. 103. Otro emigrado calificó a Poupet de "mort si malheureusement au Cap-Français" ("muerto tan desdichadamente en Cap.Français"). Dada la edad de Poupet (61), ello parecería sugerir que no se trataba de una muerte provocada por los años. Louis-Narcisse Baudry des Lozières, Second voyage à la Louisiane (París: chez Charles, 1803), 371. Sobre el concepto de posmemoria, ver Marianne Hirsch, "Family Pictures: Maus, Mourning, and PostMemory", Discourse 15 (Invierno 1992-93): 3-29.

28. CC, "Síndico contra Loriñak," fol. 3r. No está claro si ella estaba sola o acompañada. El uso de la primera persona del plural puede ser una manera formal de decir "yo". El cambio a la tercera persona del singular en la mitad de la frase refleja el proceso de transcripción, en el que el escribano cambiaba varias veces del discurso directo al indirecto. Sobre las regulaciones laborales, ver a Gabriel Debien, "Documents. Aux Origins de l'Abolition de l'Esclavage. Proclamations de Polverel et de Sonthonax 1793-1794", Revue d'histoire des colonies 37 (1949): 24-55, 348-423.

29. "R. Carta otorgando al gobernador de Santo Domingo facultad para declarar libres los esclavos que llegaran huyendo de Saint Domingue," Aranjuez, Mar. 26, 1793, reimp. en Manuel Lucena Salmoral, Regulación de la esclavitud negra en las colonias de América Española (1503-1886): Documentos para su estudio ([Alcalá?], 2005), 259-60 (cita, 259).

30. Brigadier Matías de Armona al Gobernador García, ago. 27 y 30, 1793, Exp. 52, Leg. 6855, Secretaría de Guerra, Archivo General de Simancas, consultado a través de PARES. Sobre la vida 
en los campamentos insurgentes del sur, véase Terry Rey, The Priest and the Prophetess: Abbé Ouvière, Romaine Rivière, and the Revolutionary Atlantic World (New York: Oxford University Press, 2017).

31. Ferrer, Freedom's Mirror, 106-24.

32. [Marqués de Casa Calvo?] a Joaquín García, Sept. 30, 1794, transcr. en Antonio del Monte y Tejada, Historia de Santo Domingo (Santo Domingo, 1890), 4: 275-77. Puede ser que Coleta haya sido una de las expulsadas, lo que explicaría su uso del verbo " regresar" para describir su llegada a Bayajá.

33. Véase la discusión acerca del testimonio de Ramona Jacoba más adelante.

34. Los registros bautismales de Fort Dauphin/Bayajá muestran a soldados y civiles españoles actuando como padrinos de niños nacidos de madres negras, sugiriendo paternidades levemente escondidas o reciprocidades ofrecidas a mujeres que les habían dado alguna forma de ayuda. Véase por ejemplo "Baptême de Rosinne, fille illégitime de Rose négresse", abr. 4, 1796, État Civil, Saint-Domingue, Paroisse du Fort-Dauphin, 1796, fol. 14, ANOM (a través de IREL [Instruments de recherche en ligne], http://anom.archivesnationales.culture.gouv.fr/). El padrino aparece inscrito como Antoine Castre, quien firmó como Antonio Castro.

35. CC, "Síndico contra Loriñak, fol. 3v. Manuela Sainte reportó que Coleta trabajó para ella en Bayajá y que recibió un pago acorde. Véanse las preguntas que se le hicieron a Sainte en "Síndico contra Loriñak," fol. 26r, y sus respuestas en fol. 110v.

36. Véase Gordon Forbes a Henry Dundas, enero 7, 1796, fol. 8r, Letterbook of Maj.-Gen. Gordon Forbes, Add. MSS 39824, British Library; Ferrer, Freedom's Mirror, 120-25, 138; Graham T. Nessler, An Islandwide Struggle for Freedom: Revolution, Emancipation, and Reenslavement in Hispaniola, 17891809 (Chapel Hill, N.C.: University of North Carolina Press, 2016); José Luis Belmonte Postigo, "Bajo el negro velo de la ilegalidad. Un análisis del mercado de esclavos dominicano, 1746-1821," Nuevo Mundo Mundos Nuevos, julio 7, 2016 https://nuevomundo.revues.org/69478; Ulrickson, "Cultivators, Domestics, and Slaves".

37. Véase la correspondencia en "Gobernador Habana sobre familias llegadas de Santo Domingo", junio 28,1796 , Núm. 142, Leg. 5B, así como correspondencia adicional en Legs. 5A y 5B, todos en Estado, AGI, consultado a través de PARES.

38. CC, "Síndico contra Loriñak", f. $3 \mathrm{v}$

39. CC, "Síndico contra Loriñak", f. 3v y "Segunda lista. . .desde 23 de junio de 1796", folios 136, 159.

40. La partida de bautismo incluía a una madrina (María Madalena Francesa), pero no mencionaba el nombre del padre. Ver una copia de la entrada de Inés Paula, "hija de María Luisa morena esc[lav]a" de D[oñ]a Franc[isc]a Loriñac", 20 de julio de 1801, en "Síndico contra Loriñak", folio 92r; y directamente en el Libro de Bautismos, Pardos y Morenos, Número 12, Santo Ángel Custodio, disponible en Slave Societies Digital Archive (SSDA), https:// www.slavesocieties.org/.

41. Ver "Síndico contra Loriñak", fol. 95r. Jean Hébrard ha demostrado que en Brasil muchas mujeres, esclavizadas y libres, agregaban nombres (usualmente devocionales) cuando regresaban para actos sacramentales sucesivos. Hébrard, "Esclavage et dénomination: Imposition et appropriation d'un nom chez les esclaves de la Bahia au XIXe siècle", Cahiers du Brésil Contemporain, no. 53/54 (2003)" 31-92. Ver también Sarah Abel, George F. Tyson y Gisli Paulsson, "From Enslavement to Emancipation: Naming Practices in the Danish West Indies", Comparative Studies in Society and History 61, no. 2 (Abril 2019): 332-65. Hemos considerado la posibilidad de que "Coleta" sea una versión de un apellido (tal vez Colet), y no un nombre cristiano. Sería, sin embargo, sumamente inusual que un sacerdote le diera un apellido diferente a Lorignac a una mujer joven a quien describió como esclava de Lorignac. Más aún, en la demanda póstuma, los testigos casi siempre se refieren a ella simplemente como Coleta, lo cual parece confirmar que no se trataba de un apellido. 
42. Ver Novena de Santa Coleta Virgen, Fundadora de la segunda reforma de la Religión Seráfica de N. P. S. Francisco, que compuso una religiosa Capuchina del Convento de Jesús, María y Joseph, de la Corte del Perú. Reimprímese a expensas de las Madres Capuchinas de la Ciudad de Oaxaca. . (Ciudad de México, 1795). Agradecemos a Richard Reinhardt por haber localizado esta obra en la Biblioteca John Carter Brown, Providence, R. I. Ver también Elisabeth Lopez, Colette of Corbie (1381-1447): Learning and Holiness, ed. Elise Saggau, trans. Joanna Waller (St. Bonaventure, N.Y., 2011), 498-506; y Anna Campbell, "Colette of Corbie: Cult and Canonization," en A Companion to Colette of Corbie, ed. Joan Muller y Nancy Bradley Warren (Boston, 2016), 174-206.

43. Para el festival, ver José Martín Félix de Arrate, Llave del Nuevo Mundo; Antemural de las Indias Occidentales. La Habana descripta: Noticias de su fundación, aumentos y estados (1830; repr., La Habana, 1964), 232.

44. En los registros sacramentales de la iglesia del Santo Ángel Custodio están María Loreto, hija de "Luisa Coleta morena criolla", dic. 6, 1803, y María del Socorro, hija de "Luisa negra criolla", abr. 28, 1806. Ver "Síndico contra Loriñak", fols. 95r ("morena"), 93r ("negra"). Altagracia se menciona en el testimonio de Isabel de la Sablonnière, en "Síndico contra Loriñak", fol. 108r. La hija de Andrea, la amiga de Coleta, se llamaba María Monserrate, como se indica en el fol. 14r y en la página de la cubierta del expediente "Síndico contra Loriñak."

45. Ver Jennifer L. Morgan, "Partus sequitur ventrem: Law, Race, and Reproduction in Colonial Slavery," Small Axe 22, no. 1 (no. 55) (marzo 2018): 1-17 (“aumento," 9); Catherine Hall, "Gendering Property, Racing Capital," History Workshop Journal 78, no. 1 (otoño 2014): 22-38; Jennifer L. Morgan, Laboring Women: Reproduction and Gender in New World Slavery (Philadelphia: University of Pennsylvania Press, 2004); Camillia Cowling, Conceiving Freedom: Women of Color, Gender, and the Abolition of Slavery in Havana and Rio de Janeiro (Chapel Hill: University of North Carolina Press, 2013).

46. Bajo la ley cubana, una partida de bautismo que registrara a una persona como esclava se consideraba como prueba suficiente del estatus de esclavo. El que lo opuesto fuera cierto -que el registro de una persona como libre al momento de su bautismo constituyera prueba concluyente de libertad- era una cuestión en disputa. Ver Aisnara Perera Díaz y María de los Ángeles Meriño Fuentes, Estrategias de libertad: Un acercamiento a las acciones legales de los esclavos en Cuba (1762-1872) (La Habana: Editorial de Ciencias Sociales, 2015), 1: 270, 270 n. 28. Ver también Jennifer L. Palmer, “'She persisted in her revolt': Between Slavery and Freedom in Saint-Domingue," Histoire Sociale/ Social History 53 (May 2020) 17-41.

47. CC, "Síndico contra Loriñak", 3v.

48. Ver la declaración de Jose Muños en los folios 111v y 112r; el interrogatorio a Manuela Sainte, folio 26r, y sus respuestas, folio 110v; y el interrogatorio a Ramona Jacoba, folio $25 \mathrm{v}$, todos en "Síndico contra Loriñak".

49. Un ensayo escrito por un jurista cubano en la década de 1830 dejaba en claro que parte de la tarea del síndico era la de "no suscitar pleitos injustos, manteniendo á los siervos bajo la debida sumicion y respeto. . ." José Serapio Mojarrieta, Esposición sobre el origen, utilidad, prerogativos, derechos y deberes de los síndicos procuradores generales de la pueblos (Puerto Príncipe: Imprenta del Gobierno, 1833) 17.

50. Su hijo Francisco, nacido antes de que Lorignac afirmara que las mujeres le pertenecían, parece haber sido menos vulnerable. Sobre las amenazas de retaliación por parte de los amos, véase Michael Zeuske, "Microhistorias de Vida y Hidden Atlantic: Los 'Africanos' Daniel Botefeur y Robin Botefeur en África, en el Atlántico y en Cuba," Millars: Espai i Història 42, no. 1 (2017): 15191, esp. 185.

51. El derecho de Lorignac para comerciar fue cuestionado en un momento, pero fue ratificado. Véase "Francisca Lorignac solicita se le conceda licencia para vender una negra," 1813, Exp. 16, Leg. 167, Escribanía del Gobierno, ANC. 
52. Sobre la compra de Josefa, de La Bella Gaditana, en 1810 y la venta en 1817, véase "Venta real, Lorignac," Mar. 14, 1817, Protocolos Notariales de Pontón, 1817, fol. 275v, ANC. La venta de la otra Josefa aparece en: Venta de Doña Francisca Loriñac, vecina de esta ciudad, a favor de Don Basilio Espinosa," feb. 1, 1811, Protocolos Notariales de Pontón, 1811, fol. 34v, ANC. La venta de Rafaela está en "Venta de Doña María Francisca Loriñac a Doña María de Jesús Suárez," junio 26, 1811, Protocolos Notariales de Pontón, 1811, fol. 414, ANC.

53. La casa original en ese lugar está desplomada, aunque todavía son visibles las líneas básicas de una morada de una planta y un arco de piedra (las casas en Amargura fueron renumeradas. La número 27 era, en 2019, la no. 309).

54. Véase Luis A. Francés Santana y Francisco F. Navarrete Quiñones, "San Felipe Neri, la Congregación de los Oratorianos en Cuba. Aportes arqueológicos", Gabinete de Arqueología, año 6, no. 6 (2007): 40-48; Josefina Ortega, “Oratorio San Felipe Neri: Una casa de 'congregaciones' sucesivas", La Jiribilla: Revista de Cultura Cubana 9 (dic. 18-24, 2010), http://www.lajiribilla.co.cu/ 2010/n502_12/502_04.html. La petición de Coleta de ser atendida por Fray Félix está en CC, "Síndico contra Loriñak", fol. 3v.

55. Ver Miguel Anxo Pena González, "Una propuesta antiesclavista de primera hora: el Servi Liberi de Epifanio de Moirans”, Summa Historiae: Revista de Estudios Latinoamericanos (Lima, Perú) 2 (2007): 29-70. Epifanio de Moirans, A Just Defense of the Natural Freedom of Slaves: All Slaves Should be Free (1682), trad. Edward R. Sunshine (Lewiston, ME: Edwin Mellen Press, 2007).

56. Sobre la misión de los capuchinos en Luisiana, ver Antonio de Castillo, La Luisiana española y el Padre Sedella ([San Juan, Puerto Rico: Real Hermanos], 1929), 16-43.

57. Ver padre Félix de Quintanar a obispo Luis Peñalver y Cárdenas, 27 de diciembre de 1795; y obispo Luis Peñalver y Cárdenas a padre Félix de Quintanar (Galveztown), 7 de enero de 1796, ambas en Archdiocese of New Orleans Collection (ANO), University of Notre Dame Archives, Notre Dame, Indiana (UNDA). El obispo escribió "Supongo como V. R. me dice qe ha exortado sus feligreses, no casen los Negros ellos mismo, y les permitan venir a la Yglesia a cumplir con el precepto y qq no le obedecen...".

58. El itinerario de fray Félix se puede seguir en Castillo, La Luisiana española, y en la historia mecano escrita de la orden capuchina en Cuba, que ahora se guarda en los Archivos de la Arquidiócesis de La Habana (AAH). La carta de renuncia de Félix, de fecha 13 de diciembre de 1813, se encuentra en el No. 8, Legajo 9, Capuchinos, Serie Religiosos, AAH. Sobre los capuchinos de San Felipe Neri, ver Luis A. Francés Santana y Francisco F. Navarrete Quiñones. "San Felipe Neri, la Congregación de los Oratorianos en Cuba. Aportes arqueológicos", Opus Habana, 24 (noviembre de 2010).

59. Tomo de 1784-1785, folio 73, Actas Capitulares del Ayuntamiento de la Habana (trasuntadas), Archivo de la Oficina del Historiador de la Ciudad, La Habana. Un historiador de Cuba de principios del siglo XIX, cuyos escritos no solían ser favorables a las órdenes religiosas, excluía de sus críticas a los capuchinos: "Estos religiosos gozan de la mejor reputación por lo ajustado de su vida y el empeño con que llenan en beneficio público sus obligaciones espirituales." Antonio Valdés. Historia de la isla de Cuba (1813; reedición La Habana: Comisión Nacional Cubana de la UNESCO, 1964) 349.

60. CC, "Síndico contra Loriñak". Un lector anónimo de nuestro artículo observó concisamente que Coleta había tratado de nombrar a fray Félix no sólo como su cura de almas, sino también como su agente de negocios.

61. CC, "Síndico contra Loriñak".

62. A la vez, tomó precauciones seculares, ya que parece ser que le pidió a otra refugiada, María Dolores Suárez Danau, que cuidara de sus hijas y tratara de protegerlas de una eventual venta por Lorignac. Ver la pregunta preparada por el síndico para plantearle a María Dolores Duárez Danau, "Síndico contra Loriñak", folio 25v: "si es verdad que la última vez q e. vio a la citada Coleta hallándose bien enferma la suplicó mirase por sus hijos que $\mathrm{M}^{\text {me. }}$ Larignac quería vender por 
esclavos". Parece que, al final, Suárez Danau, una mujer que posteriormente fue propietaria de un cafetal en las alturas cercanas a La Habana, no fue entrevistada. Sobre su cafetal y sus vínculos con Sendrey, ver "Luis Alejandro Sendrei pide se elimine el embargo de unos esclavos suyos que impuso el capitán del partido de Cayajabos", abril de 1828, Exp. 6, Leg. 128, Escribanía de Cabello Ozeguera, ANC.

63. Laura F. Edwards analiza reclamos legales a nivel local como apelaciones a la paz pública, hechos por medio de argumentos que se traslapan. Ver Edwards, The People and Their Peace:Legal Culture and the Transformation of Inequality in the Post-Revolutionary South (Chapel Hill, N.C., 2009). Sobre la evolución de conceptos de derechos entre litigantes esclavizados en América Latina colonial, ver Bianca Premo, The Enlightenment on Trial: Ordinary Litigants and Colonialism in the Spanish Empire (New York, 2017), cap. 6. Sobre la transmisión potencial del estatus de libre por una madre reclamada como esclava, ver Pedro Jimenez Cantisano and Mariana Armond Dias Paes, "Legal Reasoning in a Slave Society (Brazil, 1860-88)," Law and History Review 36, no. 3 (August 2018): 471-510.

64. CC, "Síndico contra Loriñak", folio $4 \mathrm{r}$.

65. Le agradecemos a Richard Reinhardt por habernos señalado los ecos de Moirans. La palabra "usurpado" no aparece en el original en latín de Moirans, aunque es el término que el traductor al inglés (Edward Sunshine) utiliza para la frase quia semper possessio stat pro libertate naturali nigrorum. Moirans observa también "[N]ec ulla consuetudo aut usus, quae abusus et corruptela dicenda sunt praevalent in contrarium: qui semper ius habent naturale ad suam libertatem et possessio stat pro libertate. Per consequens omnes filii eorum et nepotes iniuste possidentur et iure naturali liberi sunt sicut et patres eorum, iniuste servi, et contra legem naturalem mancipia", Morians, A Just Defense, 100 y 101 (citas), 95, 99.

66. CC, "Síndico contra Loriñak".

67. La distintiva letra de fray Félix se puede apreciar en su carta de renuncia al obispo de La Habana. Exp. 8, Leg. 9, Capuchinos, Serie Religiosos, AAH.

68. CC, "Síndico contra Loriñak", folio $3 \mathrm{v}, 4 \mathrm{r}$.

69. La entrada tiene fecha del 13 de enero de 1817, y está en el folio 157 del Libro Sexto de Pardos y Morenos, No. 953, Archivo de la Iglesia del Santo Ángel, La Habana.

70. Para evidencia y análisis procedentes de múltiples jurisdicciones, ver dos números especiales de revista: Camillia Cowling, Maria Helena P. T. Machado, Diana Paton y Emily West, "Mothering Slaves: Motherhood, Childlessness and the Care of Children in Atlantic Slave Societies," Slavery and Abolition, 38 (2017); y Cowling, Machado, Paton, y West, "Mothering Slaves: Motherhood, Childlessness and the Care of Children in Atlantic Slave Societies," Women's History Review, 27 (2018).

71. En cambio, un miembro de la familia Aurignac de Saint-Domingue, Geneviève Aurignac, veuve Cappé, le escribió una carta suplicante al gobierno francés desde su lugar de refugio en el antiguo seminario de L'Esquile, en Toulouse, rogando que se le concediera alguna ayuda financiera. Ver Aurignac, $\mathrm{V}^{\mathrm{ve}}$, en F/12/2743, ANP; J. Adher, "Les Colons réfugiés d'Amérique pendant la Révolution", Bulletin de la Société de Géographie de Toulouse 34 (1915): 152-168.

72. Cuando se le preguntó más tarde acerca de Coleta: "Si habiendola visto tratar en esta Ciudad como esclava la aconsejó no lo consintiera y q se presentara a reclamar sus dros", Jacoba respondió afirmativamente. Ver folios $25 \mathrm{v}$ y 110r, "Síndico contra Loriñak". Sobre Biassou y Jacoba, ver Records of East Florida, Library of Congress, incluida Ramona Jacoba a Governor of East Florida Enrique White, 4 de mayo de 1803, disponible en microfilme, Rollo 83, Sección 45, Papers on Various Subjects, 1783-1821; Alain Yacou, "La présence française dans la partie occidentale de l'île de Cuba au lendemain de la révolution de Saint-Domingue", Revue française d'histoire d'outre-mer 74, no. 275 (1975): 149-188; Jane G. Landers, Atlantic Creoles in the Age of Revolutions (Cambridge, MA: Harvard University Press, 2011), 92-93, 285. 
73. Ver "Obligación”, 8 de marzo de 1818, Vol. I, 1818, folios 309v-310r, Protocolos Notariales de Pontón, ANC. Ver también "Luis Alejandro Sendrey contra Francisca Lorignac reclamando dinero, [1819]", Exp. 7805, Leg. 611, Escribanía de Salinas, ANC (que abreviamos como "Sendrey contra Lorignac").

74. Ver "Obligación", 8 de marzo de 1818, Vol. I, 1818, folios 309v-310r, Protocolos Notariales Pontón, ANC, y “Obligación”, 19 de diciembre de 1818, Vol. II, 1818, folios 1758-1759, Protocolos Notariales Pontón, ANC. Es posible que en determinado momento Sendrey llegara a creer que obraba en su interés y en el de Lorignac desplazar la propiedad formal de las hijas de manos de Loringac, acusada de esclavización ilegal intencional, y pasarla al itinerante Sendrey, quién podía afirmar que la había adquirido de buena fe.

75. La deuda de Lorignac con Miró, Pie \& Cia por la compra de bozales aparece en una querella de 1819 en "María Francisca Lorignac contra Juana de los Santos García sobre dinero", Exp. 5, Leg. 687, Escribanía de Daumy, ANC.

76. Ver Mojarrietra, Exposición, 17. Mojarrieta estimaba que la intervención de un síndico era apropiada en casos que involucraran a esclavos, porque el esclavo estaba sujeto en todos los aspectos a la potestad dominica del amo, lo que hacía imposible toda disputa legal entre ellos. (“... los esclavos no tienen persona: carecen de representación en la sociedad: se consideran como cosa sujeta a dominio de los hombres. . ."). La práctica era más flexible que la teoría, y quejas planteadas por personas sometidas a la esclavitud en ocasiones llegaban directamente a los alcaldes locales. Ver Perera y Meriño, Estrategias, Vol. 1, 136. El concepto de personalidad legal es complejo y objeto de polémicas. Generalmente se refiere a la posesión de derechos en defensa de los cuales se puede establecer un juicio formal en nombre propio. En ocasiones, los historiadores lo utilizan para referirse más ampliamente a la capacidad de iniciar una acción legal o presentarse ante un tribunal de alguna manera. Ver Kimberly M. Welch, Black Litigants in the Antebellum American South (Chapel Hill: University of North Carolina Press, 2018).

77. Ver Claudia Varella, "El canal administrativo de los Conflictos entre Esclavos y Amos. Causas de Manumisión Decididas ante Síndicos en Cuba”, Revista de Indias 71 no. 261 (2011): 109-36.

78. Para demandas de libertad realizadas por personas tenidas como esclavas o esclavos que llegaron al alcalde local directamente, ver Perera y Meriño, Estrategias, Vol. 1, 136; y Chira, "Affective Debts".

79. La historiografía sobre pleitos para la libertad es muy amplia. Sobre Cuba, ver Perera and Meriño, Estrategias; Chira, "Affective Debts"; Alejandro de la Fuente, "Slaves and the Creation of Legal Rights in Cuba: Coartación and Papel," Hispanic American Historical Review 87 (November 2007): 659-692; Waldomiro Lourenço da Silva Junior, História, direito e escravidão: A legislação escravista no Antigo Regime Ibero-Americano (São Paulo, 2013); Varella, "El Canal Administrativo"; Julio Ramos, "La ley es otra: Literatura y constitución de la persona jurídica", Revista de Crítica Latinoamericana 20, no. 40 (1994): 305-35. Para una discusión de la historiografía de los Estados Unidos, ver Kelly Kennington, In the Shadow of Dred Scott: St. Louis Freedom Suits and the Legal Culture of Slavery in Antebellum America (Athens, 2017), y Alfred L. Brophy, "Slaves as Plaintiffs," un ensayo sobre Lea VanderVelde, Redemption Songs: Suing for Freedom Before Dred Scott (New York, 2014), en Michigan Law Review 115 (April 2017): 895-914. Sobre Brazil, ver Sidney Chalhoub, A força da escravidão: ilegalidade e costume no Brasil oitocentista (São Paulo, 2012); Beatriz G. Mamigonian y Keila Grinberg, "Le crime de réduction à l'esclavage d'une personne libre (Brésil, XIXe siècle)", Brésil/s (Paris) 11 (2017), y la historiografía que cita. Sobre Perú colonial, ver Michelle McKinley, Fractional Freedoms: Slavery, Intimacy, and Legal Mobilization in Colonial Lima, 1600-1700 (New York, 2016). Sobre Chile, ver Carolina González Undurraga, Esclavos y esclavas demandando justicia. Chile, 1740 - 1823. Documentación judicial por carta de libertad y papel de venta (Santiago de Chile, 2014). Sobre Mexico, ver Brian Owensby, "How Juan and Leonor won their freedom: Litigation and liberty in seventeenth-century Mexico", Hispanic American Historical Review 85 (2005) 39-80. Sobre América Latina colonial, ver Premo, Enlightenment on Trial, ch. 6. 
80. Ver la correspondencia durante el período en que Félix fue dirigente de los capuchinos de La Habana en Serie Religiosos, AAH.

81. Sendrey creía que el caso se había iniciado a partir de una denuncia a Lorignac hecha por una de sus sobrinas. (Puede haberse referido a su prima Isabel de la Sablonnière.) También es posible que la mayor de las hijas, Inés, se hubiera dirigido a la Plaza de Armas y presentado una queja directamente al síndico. "Sandrey contra Lorignac", folio 14.

82. En 1806 a Sendrey se le menciona en periódicos de los Estados Unidos como capitán de la goleta United States. Ver "Ship News", City Gazette (Charleston, Carolina del Sur), 8 de julio de 1806, p. 3; y "Singular Phenomenon", Norfolk Gazette and Publick Ledger, 13 de marzo de 1806, 2. En 1809 se le incluyó en una lista de residentes franceses en Cuba, la mayoría de los cuales estaban a punto de ser expulsados de la isla tras la invasión napoleónica a España. Ver folio 16 de Libro 2014, Miscelánea de Libros, ANC, en el que Luis Sandret, soltero, se describe como propietario de tierra y dueño de 12 esclavos. En "Síndico contra Loriñak", folios 32r, 32v, aparece (fonéticamente) como Sr. Luis Andrés.

83. "Sendrey contra Lorignac," fol. $6 r$.

84. "Síndico contra Loriñak", folios 1r, 1v, 2r, 2v. Filomeno poseía a su fallecimiento en 1835 un ingenio y un cafetal evaluados en más de 300,000 pesos con numerosos trabajadores esclavizados. Testamentaría del Sor. Francisco Filomeno Ponce de León. Exp. 832, Leg. 94, Escribanía de Marina, ANC. Sobre juristas y esclavitud, ver Bianca Premo, "An Equity Against the Law: Slave Rights and Creole Jurisprudence in Spanish America," Slavery and Abolition 32 (December 2011): 495-517.

85. Un bosquejo biográfico de Filomeno aparece en Antonio L. Valverde, Jurisconsultos cubanos. Biografías y Retratos (La Habana: Cultural, 1932) 105-l16.

86. "Síndico contra Loriñak", folios $1 \mathrm{r}, 1 \mathrm{v}$ y 2r. Hay una disposición en las Siete Partidas que permite un juicio por parte de los herederos a nombre de una persona libre erróneamente tenida por esclava en el momento de su muerte. Ver Partida III, Título XXIX, Ley XXV, Siete Partidas. No obstante, el síndico no echó mano de esa disposición. En lugar de ello, asumió que Coleta era libre en el momento de su arribo a Bayajá, e invocó la protección brindada a los refugiados de SaintDomingue por la corona española. Ver la petición de Filomeno de 23 de noviembre de 1819 en folios 1r, 1v, 2r, "Síndico contra Loriñak".

87. "Sendrey contra Lorignac", folio 6. El nombre de Lorignac no aparece en el censo de residentes de Jesús del Monte realizado por autoridades eclesiásticas en 1820. "Padrón nominal de los habitantes de la parroquia de Jesús del Monte, La Habana, 1820”, Exp. 29379, Leg. 869, Gobierno Superior Civil, ANC.

88. Reconociendo que Sendrey no había recibido el pago que correspondía y que era posible que no pudiera tomar posesión de las hijas, el juez asignado al caso también embargó una parte de los alquileres que Lorignac percibía por su casa de la calle Amargura en La Habana. Ver "Sendrey contra Lorignac", folios $15 \mathrm{r}$ y $15 \mathrm{v}$.

89. "Síndico contra Loriñak", folio $19 r$.

90. "Sendrey contra Loriñak," fols. 49r, 49v, 50v; "Síndico contra Loriñak,"fols. 18r, 18v.

91. Sobre la llegada de las noticias sobre la Constitución, ver Olga Portuondo Zúñiga, Cuba. Constitución y liberalismo 2 vols. (Santiago de Cuba: Editorial Oriente, 2008) I: 125-138, 201.

92. Ver "Síndico contra Loriñak", folios 25-28; y Memorias de la Sociedad Patriótica de la Habana, Vol. X (La Habana: Imprenta del Gobierno y Capitanía General, 1840) 318. Filomeno había abandonado el cargo de síndico a fines de diciembre de 1819 y Fernández de Velazco lo sustituyó. Este fue reemplazado como resultado de las elecciones especiales.

93. "Síndico contra Loriñak", folios 35r-37r.

94. "Síndico contra Loriñak", folios $8 \mathrm{r}, 8 \mathrm{v}$.

95. Sobre este tipo de procedimiento, ver Perera y Meriño, Estrategias, vol 1, 119.

96. Los interrogatorios aparecen en los folios $25 r$ a 28r, "Síndico contra Loriñak". 
97. La política del segundo período constitucional, que concluyó en diciembre de 1823 con la revocación de la Constitución, se analiza en Oscar Zanetti, Historia mínima de Cuba (México, D.F.: Colegio de México, 2013) 127-136.

98. Portuondo, Cuba, I: 181.

99. El debate en torno a los capuchinos se describe en la historia mecanografeada de la orden capuchina que se conserva en los Archivos de la Archidiócesis de La Habana. Sobre la regla de que los capuchinos siempre debían ir acompañados, ver la Constitución de los Capuchinos de 1536, traducida por Paul Hanbridge y publicada por el Collegio San Lorenzo da Brindisi (2006), 10: "Además les orientamos a los frailes que no anden solos sino con su acompañante, según el ejemplo de los santos discípulos del santísimo Salvador... Ni tampoco deben andar sin la debida obediencia escrita de su superior estampada con el sello del Padre Vicario o el sello del lugar". Acceso en https://capuchins.org/documents/Constitutions1536.pdf.

100. La frase aparece en la carta de diciembre de 1795 de fray Félix al obispo de Nueva Orleáns, ANO, UNDA.

101. Las declaraciones de German Tourtour, Carlos Asselin y José Claret, testigos de Lorignac, aparecen en los folios 100r-107r, y los de los testigos de las hijas en los folios 108r-111v, "Síndico contra Loriñak".

102. "Síndico contra Loriñak", folio $8 \mathrm{v}$.

103. Las preguntas a los testigos de Lorignac están en los folios 96r-97v; las respuestas de Claret aparecen en los folios 104r, 104v, 105r; todos en "Síndico contra Loriñak".

104. "Síndico contra Loriñak", folios $96 r$ - 97r.

105. "Síndico contra Loriñak", folios 27r, 108r-112r. El síndico indicó que el dueño de Andrea había muerto sin venderla. Sobre la oferta de protección en 1793, ver Lucena Salmoral, Regulación, 259.

106. "Síndico contra Loriñak", folios $108 \mathrm{r}-112 \mathrm{r}$, cita en $111 \mathrm{v}$.

107. Más información sobre la familia Bigeon Sablonnière se encuentra en Marcel Grandière, "Les réfugiés et les déportés des Antilles à Nantes sous la Révolution”, Bulletin de la Société d'Histoire de la Guadeloupe 33-34 (1977): 3-171; y en la lista de pasajeros de que partieron de Nantes “07/02/1785 pour Saint Marc, Elisabeth Marguerite Bigeon, fille d'André, 23 ans". Le agradecemos a Bernadette Rossignol, de la sociedad Généalogie et Histoire de la Caraïbe, por este último dato.

108. Las preguntas a Sablonnière están en los folios $26 \mathrm{r}, 26 \mathrm{v}, 27 \mathrm{r}$, y sus respuestas en los folios 108r y 108v, "Síndico contra Loriñak".

109. "Síndico contra Loriñak," folios 56r-76r, cita 64r. El poder de 1821 está transcrito en los folios 42r y 42v, "Síndico contra Loriñak". En febrero de 1822, D. Francisco de Encinoso de Abreu ya era el nuevo síndico. Ver "Síndico contra Loriñak", folios 56r-76r. Para detalles sobre los sucesivos síndicos con jurisdicción en La Habana, ver Memorias de la Sociedad Patriótica, Vol. 10 (La Habana: Imprenta del Gobierno y Capitanía General, 1840), 317, 318.

110. Ver la decisión del Alcalde de Primera Elección, de fecha 22 de abril de 1822, en "Síndico contra Loriñak", folios 68v, 69r, 69v.

111. "Deseo saber la casa donde se encuentran hoy mis defendidas. . . pues acaso me será prec[iso] recibir alga. instruccion de las $\mathrm{m}$ [is]mas sobre este asunto. .". Su otra frase era "negandole el dominio sobre cuatro infelices de condición libre". "Síndico contra Loriñak", folios $76 \mathrm{v}, 77 \mathrm{r}, 78 \mathrm{r}, 81 \mathrm{r}$.

112. "Síndico contra Loriñak", folios 80v-85r.

113. La orden está en "Síndico contra Loriñak", folio $85 \mathrm{v}$.

114. "Síndico contra Loriñak", folios 89v, 90r. Escovar/Escobar era un apellido corriente entre los libres de color de La Habana, incluidos miembros de la milicia y el famoso pintor Vicente Escobar y Flores. 
115. El tribunal emitió una orden general a ese efecto. "Síndico contra Loriñak", folio 87r-89r. Sobre la historia más general del papel de las partidas de bautismo como marcadores de estatus y nacionalidad, ver Tamar Herzog, "Naming, Identifying and Authorizing Movement in Early Modern Spain and Spanish America", en Keith Breckenridge y Simon Szreter, Registration and Recognition. Documenting the Person in World History (Oxford: Oxford University Press, 2012), 191-209.

116. Archivo de la Iglesia del Santo Ángel, La Habana. Sobre la campaña del obispo Juan José Díaz de Espada para controlar el mantenimiento de los registros y para evitar la introducción de enmiendas, lo cual podía ser una fuente de corrupción, ver Consolación Fernández Mellén, Iglesia y Poder en La Habana: Juan José Díaz de Espada, un obispo ilustrado (1800-1832) (Bilbao: Universidad del País Vasco, Servicio Editorial , 2014), 252-53. Los archivos de la Arquidiócesis de La Habana contienen una sección denominada Justicia, que contiene una serie llamada Procesos Legales y una subserie titulada Enmiendas. Desafortunadamente, los registros de esta sección están incompletos para el periodo anterior a 1850. Podrían emerger nuevos materiales a medida que los legajos sin catalogar se hagan disponibles para los investigadores. Ver Fundación Histórica Tavera, Archivo Histórico del Arzobispado de La Habana: Inventarios: Informe y resultados de un proyecto de cooperación archivística internacional (Madrid, 2001).

117. "Síndico contra Loriñak," fols. 120, 121.

118. Para notables redes de declaraciones sobre el estatus que atravesaban fronteras y océanos, ver Nancy E. Van Deusen, Global Indios: The Indigenous Struggle for Justice in Sixteenth-Century Spain (Durham: Duke University Press, 2015).

119. Francisco Filomeno y Sebastián Fernández de Velazco habían representado a los lados opuestos en el dramático juicio a Manuel Rodríguez Alemán, acusado de espiar para José Bonaparte. Fernández de Velazco fue el juez en el juicio por conspiración seguido a José Antonio Aponte. Ver Antonio L. Valverde, Jurisconsultos cubanos: biografías y retratos (La Habana: Cultural, 1932) 105-127.

120. La petición oficial de Filomeno se encuentra en "Síndico contra Loriñak", folios $1 \mathrm{r}, 1 \mathrm{v}, 2 \mathrm{r}$.

121. Por ejemplo, James Sweet, Domingos Álvares, African Healing, and the Intellectual History of the Atlantic World (Chapel Hill, N.C., 2011); Scott and Hébrard, Freedom Papers; John-Paul Ghobrial, "The Secret Life of Elias of Babylon and the Uses of Global Microhistory", Past and Present, no. 222 (February 2014): 51-93; Lisa A. Lindsay, Atlantic Bonds: A Nineteenth-Century Odyssey from America to Africa (Chapel Hill, N.C., 2017). See also Romain Bertrand and Guillaume Calafat, "La microhistoire globale: Affaire(s) à suivre", Annales: Histoire, Sciences Sociales 73, no. 1 (March 2018): 3-18.

122. Hendrik Hartog introdujo la frase "law-bound conspiracy" (conspiración vinculada con, y restringida por, la ley) para referirse a estrategias de este tipo. Hartog, en The Trouble with Minna: A Case of Slavery and Emancipation in the Antebellum North (Chapel Hill: University of North Carolina Press, 2018) 75.

\section{NOTAS FINALES}

i. 


\section{RESÚMENES}

Este artículo explora el proceso de esclavización de personas libres en sociedades en las que esas acciones eran teóricamente ilegales. Al dejar Saint-Domingue poco después de la abolición formal de la esclavitud, ¿podía la joven Marie Louise (posteriormente llamada María Luisa Coleta) preservar la libertad legal que había alcanzado allí? En la Cuba de 1796 la respuesta parecía ser "no". Durante veinte años fue sometida en La Habana a la condición de esclava por María Francisco Lorignac, una refugiada como ella que había pagado el pasaje de la joven a Cuba. Pero cuando en diciembre de 1816 un fraile capuchino se preparaba para administrarle los últimos ritos a Coleta en su lecho de muerte, esta le imploró que pusiera por escrito su narración y la presentara a un juez para iniciar un juicio a favor de la libertad de sus hijas. Solo después de que fray Félix accediera a hacerlo, ella aceptaría la absolución. Dos años más tarde, una apelación a favor de las hijas de Coleta finalmente llegó a los tribunales. El expediente resultante revela la profunda indeterminación del estatus surgida de la revolución haitiana y refleja los obstáculos para obtener una reparación legal en la sociedad esclavista cubana. Se inicia con la transcripción de la "confesión" de Coleta que, en un momento final de coraje, contó la historia de una vida humilde transcurrida entre imperios y expresó su convicción de que era una mujer libre ilegalmente sometida a la esclavitud, y que sus hijas no debían correr la misma suerte.

\section{ÍNDICE}

Mots-clés: esclavage, liberté, femmes, Cuba, révolution de Haïti

Keywords: slavery, freedom, women, Cuba, Haitian Revolution

Palabras claves: esclavitud, libertad, mujeres, Cuba, revolución de Haití

\section{AUTORES}

\section{REBECCA J. SCOTT}

Charles Gibson Distinguished University Professor of History y Professor of Law de la Universidad of Michigan

\section{CARLOS VENEGAS FORNIAS}

Licenciado en Historia del Arte, Investigador Auxiliar del Instituto Cubano de Investigación Cultural Juan Marinello, La Habana, Cuba 